\title{
Community-Mindedness: Protection against Crime in the Context of Illicit Drug Cultures?
}

\author{
Anke Stallwitz \\ Professor of Social and Community Psychology \\ Evangelische Hochschule Freiburg \\ University of Applied Sciences \\ Bugginger Strasse 38 \\ 79114 Freiburg \\ Deutschland \\ Contact author - Dr. Anke Stallwitz: stallwitz@eh-freiburg.de; (0049) (0)761- 478 12-52
}

\begin{abstract}
The heroin scene on the Shetland Islands (GB) has been investigated with the objective to obtain an encompassing and profound insight into the relationship of location- and timespecific factors impacting on the nature and characteristics of illicit drug use and its surrounding social structures. Twenty-four local heroin users with differing using styles have been interviewed in-depth. According to the Shetland heroin users, the island heroin scene had existed for approximately two decades since the late 1970s in a socially integrated and unobtrusive way. As a result of a combination of diverse micro- and macro-social influences, the subculture began to change its character significantly around the turn of the millennium: Numbers of users as well as destructive and addicted patterns of use "exploded", criminal tendencies started to become apparent, and the scene became increasingly noticeable to the general public. Interview analysis revealed a close relationship between the subculture's prevailing value system at a certain point in time, especially the strength of communitymindedness (communal spirit comprising both social care and social control), and the respective degree of subcultural crime and deprivation. The capacities of communitymindedness to prevent harm at both the subcultural and the community levels are examined, and conditions that either further or hinder the communal spirit are illuminated. The utility and applicability of the concept of community-mindedness with respect to research, policy, and practice is demonstrated.
\end{abstract}

Keywords: Illicit Drug Use; Heroin Subculture; Community-Mindedness; Shetland Islands; Drug Trend; Zeitgeist; Harm Reduction 
Community-Mindedness: Protection against Crime in the Context of Illicit Drug Cultures? Stallwitz

\section{Introduction}

For a comprehensive representation and thorough understanding of illegal drug use and its wide-ranging consequences, the phenomenon needs to be investigated in its multi-facetted individual, social, and geographical aspects. With respect to its social dimensions and circumstances, the drug related norms, values, and behaviors of the surrounding wider culture and immediate subculture have repeatedly been identified to be of great relevance in explaining the occurrence and extent of specific drug using patterns (Grund 1993; Harding and Zinberg 1977; Lalander 2003; Lempens, van de Mheet and Barendregt 2003; Stallwitz, 2012; McCurdy, Williams, Kilonzo, Rossi, and Leshabari 2005; Zinberg 1984). Concerning the geographical conditions within which the wider culture and various subcultures are embedded, both urban and rural areas must to be taken into account (cf. Dean 1990, 1995, 2001).

Culture can be defined as "the collective mental programming of the people in an environment" (Hofstede 1980, 43) and embraces the entirety of moral concepts and life forms of a community (Hillmann 1994). ${ }^{1}$ Subculture as employed in this article can be understood as a "sub-area of an encompassing culture that deliberately dissociates itself from the prevailing culture in its norms, values and manners [...] Social outsiders often amalgamate in subcultures in order to protect their deviant conduct from social control" (German Federal Agency for Civic Education [Bundeszentrale für politische Bildung] 2009, transl. by author). Prevailing (mainstream) cultures usually encompass a great variety of subcultures that entail associated values, norms, symbols, and behavioral patterns. Subcultures centered on drug use represent merely one specific variant, with the simultaneous existence of abundant others defined by diverse types of belonging, such as ethnicity, religion, and region (Golub, Johnson and Dunlap 2005).

This article examines the nature and particularities of the subcultural social structure surrounding illicit drug use by using the example of the heroin scene on the Shetland Islands. The significance of the prevailing subcultural value system becomes obvious. Specifically, the level of a general community-minded spirit is demonstrated to be central in determining a subculture's character. It is shown how this spirit can operate as a protector against crime and deprivation and in which way this protective function depends on various location- and timespecific circumstances. An understanding of these micro-social mechanisms can effectively inform innovative drug research and intervention.

\section{Location-specific drugs research}

\section{Empirical Evidence of Rural Drug Use}

Although illegal substance use still tends to be associated with urbanity, a substantial body of international research provides evidence of significant prevalence rates in nonmetropolitan regions (e.g. Anderson and Frischer 1997; Day, Conroy, Lowe, Page, and Dolan 2006; Donnermeyer 1992; Hay, Gannon, Casey and McKeganey 2009). The analysis of empirical investigations conducted at rural and urban places around the world suggest a 
gradual convergence of many non-urban to urban locations regarding the extent of illicit drug use. Studies indicating considerable degrees of rural drug use have, for example, been conducted in different states in the continental USA, (e.g. Donnermeyer, Scheer and Borden 2000; Johnston, O’Malley and Bachman 1993;), Hawaii (e.g. Waitzfelder, Engel and Gilbert 1998), and remote areas of Alaska (e.g., Hardenbergh, Stillner, Kraus and Leukefeld 1999); central America (e.g. Aldaz, Wagner, Diaz, Lopez and Collado 2002); Australia (e.g. Day, Conroy, Lowe, Page \& Dolan 2006); Arabia (e.g Mojtahedzadeh, Razani, Malekinejad, Varirian, Shoaee, Zafarghandi, Hermandez and Mandel 2008); non-urban places in Asia (e.g Chengzheng et al 2004; Nguyen and Scannapieco 2008); and rural parts of numerous countries in Europe (e.g. Abraham 1999; Baier 2004; Hay, Gannon, McKeganey, Hutchinson and Goldberg 2005).

Corresponding to the above cited studies, British research findings also provide evidence of illegal drug use extending to non-metropolitan and even extremely remote areas, such as the Scottish highlands and islands (Dean 1990, 1995, 2001; Gardner and Peck 1996; Stallwitz 2012; Stallwitz and Shewan 2004). Hay and Gannon found not only illicit drug use, but acquisitive crime to be significantly more prevalent in rural Norfolk, East England, than presumed before (2006). Some Scottish examples show that using or injecting levels in agricultural places can be at least as high as in cities (Forsyth and\& Barnard 1999; Hay, McKeganey and Hutchinson 2001; Gardner and Peck 1996; ISD Scotland 2004-2011).

As pointed out by the Scottish Executive's Effective Interventions Unit in a summary of a qualitative study on service provision for drug users in rural and remote areas of Scotland (2005): "The lower level and number of services in rural and remote areas and the possibility of drug users being supported by extended families and close knit communities without recourse to services suggest an unmeasured level of underreporting in these areas." Hence, reliable statistical comparisons between urban and rural drug using rates are difficult if not impossible to accurately measure. Consequently, estimations based on mixed-method approaches (a combination of qualitative and quantitative designs) seem most efficient and effective for examining substance use in the rural context.

\section{Defining Rural}

No common definition of 'rurality' exists in the literature. Most drugs researchers have relied on descriptive, quantifiable aspects to identify rural sites. These typically include population size and density, geographic position, accessibility, and sometimes economic and employment issues. However, such criteria can depict only the outward appearance of a place.

The inner structure and way of communal functioning, shaped by people's beliefs, values, and norms, cannot be captured quantitatively. Again, it is beliefs, values, and norms which determine such social phenomena as drug use. When attempting to define the rurality of a location accurately and comprehensively, both, the descriptive, quantifiable and the sociocultural characteristics have to be specified (cf. Stallwitz 2012, p. 32).

The Scottish Government Urban-Rural Classification applies the criteria size and geographic accessibility to urban areas to identify a place as 'rural' or 'urban'. The classification system divides urban areas into 'large urban areas', 'other urban areas', 168 I P a g e 
Community-Mindedness: Protection against Crime in the Context of Illicit Drug Cultures? -

Stallwitz

'accessible small towns', 'remote small towns', and 'very remote small towns'. Rural areas are differentiated into 'accessible rural areas', 'remote rural areas', and 'very remote rural areas' (cf. Scottish Executive 2006; Scottish Government 2012).

\section{Rurality of Scotland}

With its sparse population of 23,240 inhabitants (16 persons per square kilometer) (National Records of Scotland 2013) and 12 hour ferry distance from the nearest cities, Aberdeen in Scotland and Bergen in Norway (direct ferries, 2013), most of the Shetland Islands fall in the category of a 'very remote rural area' (Figure 1). 'Very remote' implies a more than 60-minute driving distance to the nearest town of more than 10,000 inhabitants.

With a population of approximately 7,500 people, the capital Lerwick constitutes the only town and and by far the biggest community on the islands. The population of the next biggest place, Scalloway, contains only 1,250 inhabitants (Visit Shetland 2013). Due to its busy industrial and passenger port, Lerwick might feel more urban though than other places of similar size and remoteness. Furthermore, its remarkably low population density which is the $4^{\text {th }}$ lowest in Scotland (National Records of Scotland 2013) creates an exceptionally rural impression. Yet, Sullom Voe in the very remote north of Shetland represents one of the biggest oil terminals in the world (Shetland Island Council, 2009). Particularly during the period of construction in the mid to late 1970s, the port attracted a great influx of foreign workers from the mainland of Britain (Wills 1991). Consequently, this industrial outpost of international significance contributes an urban feature to the mainly rural-appearing island group. Concerning illegal drug use, the time of construction is associated with the beginnings of the island heroin scene (Stallwitz 2007, 2012; Stallwitz and Shewan 2004).

Shetland's general socio-cultural infrastructure, though, could be designated as restricted, since institutions such as a regular theater, cinema, or a university hitherto do not exist. The communal social life of the island appears substantially shaped by its lively party and Lerwick's pub scene as well as various folk and maritime festivals (Visit Shetland 2013). Overall, Shetland's way of life (cf. Wills 1991) could be referred to as relatively traditional and non-metropolitan.

\section{Location-Specificity}

The complexity and the diversity of Shetland's characterizing features highlight the incompleteness and insufficiency of descriptive criteria, as employed by established classification systems, when attempting to situate a place on the spectrum between urban and rural. Besides the necessity of qualitative criteria becoming obvious, it seems more appropriate to speak of drug research as location-specific rather than either urban or rural per se (Dean 1990, 1995; Forsyth \& Barnard 1999). Location-specific could be employed as a super-ordinate umbrella term under which urban and rural features are classified. With this more differentiated approach, scientific investigations might gain in both inter- and intranational comparability. 


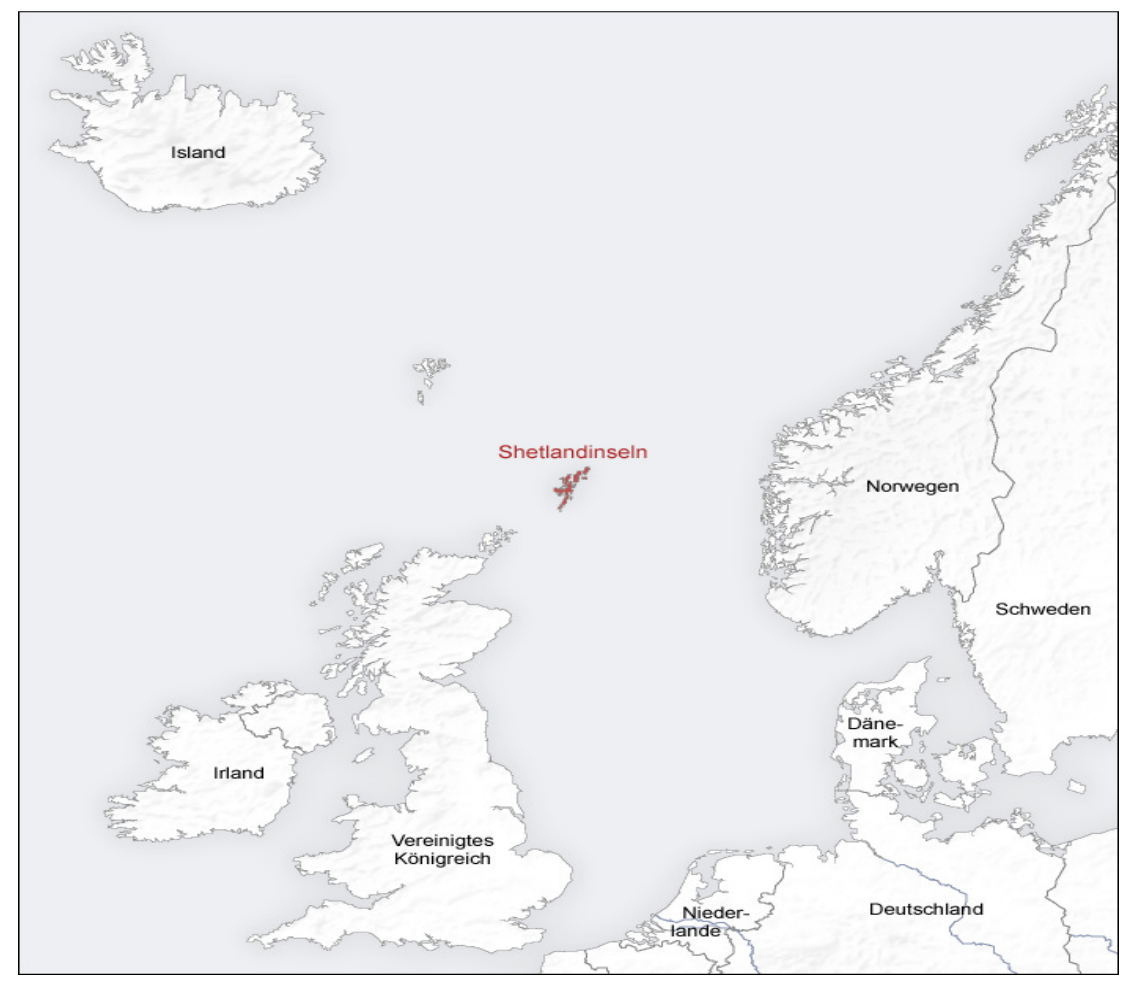

Figure 1: Shetland's Location in Relation to Scotland and Norway (San Jose 2006)

\section{Collective Efficacy and Community-Mindedness}

The wide-spread assumption of significantly lower drug using levels in rural compared to urban areas has already been mentioned. Related to this, it could be argued that the often unmeasured diversity of location-related quantitative and qualitative characteristics might be responsible for unlike outcomes of collective efficacy in communities of similar features (Sampson 2012). In contemporary criminological literature, collective efficacy has been defined as "the linkage of social control and cohesion" (Morenoff, Sampson and Raudenbush 2001, p. 517) with the effective implementation of social control being dependent on shared expectations (Sampson, Raudenbush and Earls, 1997). High levels of collective efficacy are presumed to be correlated with smaller, specifically rural communities and lower rates of illicit activities, including drug use (McVie and Norris 2006; Sampson 2012). Often social capital is regarded as closely linked to collective efficacy and a community's ability to realize and maintain social organization (Ansari 2013). Putnam understands social capital as "features of social organization, such as networks, norms, and trust that facilitate coordination for mutual benefit" (1993, p. 36) and also involve "high levels of trust and civic participation" (2000).

Although collective efficacy is commonly regarded as a protective factor against crime, this effect cannot be regarded as generally applicable. The social acceptability and function of a certain behavior - criminal and not criminal - in a specific place at a specific time fundamentally determines its frequency, intensity, and expansion. In this connection, community-mindedness might offer a normatively more open concept of overall greater 


\section{Community-Mindedness: Protection against Crime in the Context of Illicit Drug Cultures? - Stallwitz}

differentiation between and within places. Community-mindedness constitutes a multi-faceted social phenomenon that could be conceptualized as encompassing a "communal, caring attitude on the one hand and a strong degree of social control, exclusiveness, or even stigmatisation on the other hand" (Stallwitz 2012, p. 174; see Stallwitz 2012, pp. 174-175 for detailed presentation of defining characteristics of community-mindedness). ${ }^{2}$ The term community-mindedness originates from an expert study concerned with heroin use in Shetland, which is briefly described in the methodology section. An interviewed local police officer employed the term "community-minded" to characterize the representative style of dealing within the island heroin scene (Stallwitz 2007, pp. 263-264).

Even though community-mindedness resembles collective efficacy, it also diverges in several aspects. Whereas community-mindedness represents a communal spirit, an attitude, collective efficacy describes a social capacity required to become active with a certain direction, i.e. towards a shared aim. Corresponding to Sampson, a community needs a number of premising neighborhood characteristics in order to generate a social ethos that promotes dynamics protective against crime and thus furthering community safety (2004). Comparably, the development of community-mindedness depends on the realization and adherence to diverse pro-social values and behavioral rules but also clearly defined sanctions and could be understood as counteracting antisocial phenomena such as crime.

Regarding the extent of criminal tendencies within a drug subculture, the strength of community-mindedness within the subculture itself is of significant relevance. The level of community-mindedness of the surrounding community of course plays a crucial causal role here. Hence, not only on the macro-social (community) but also on the micro-social (subculture) level, community-mindedness can be understood as closely related to a general pro-social ethos.

It has been argued above that both essential quantitative and qualitative local features need to be analyzed when specifying a place's rurality or urbanity, respectively. With a special focus on the occurrence of crime, various authors have pursued a similar line of argumentation and suggested "the utilization of such concepts as gemeinschaft, cohesion, integration, collective efficacy, and social capital to describe the structural characteristics of rural places in relation to crime" (Donnermeyer 2007; Donnermeyer and DeKeseredy 2008; Deller and Deller 2010 as cited in Li 2011, p. 65; Sampson, Raudenbush and Earls 1997). Community-mindedness fits in well with these structural or socio-cultural characteristics.

With respect of the present investigation of the heroin subculture on the Shetland Islands, the significance of community-mindedness constitutes a fundamentally new finding. The communal spirit was found to be crucial in shaping both the outward appearance and the internal structure of the island drug scene. Moreover, it became apparent how its strength and influence altered over time alongside socio-cultural transformations within the embedding mainstream culture of the Shetland Islands. In the analysis chapter these complex coherences as pictured in the accounts of the interviewed Shetland Island heroin users will be illustrated and further debated against the background of relevant literature on community and crime. 


\section{Methodology}

The overall research question of the investigation was: "How do heroin users of different styles in Shetland perceive and represent the nature and socio-historical developments of the local heroin scene?"

\section{Research Location and Design}

The data collection for this study was conducted in Lerwick, the capital of Shetland, over a two month period from May until July 2004. An emergent research design was applied with the original interview guidelines being adjusted over the course of the interviews.

\section{Participants and Sampling}

Twenty-four Shetland heroin users were interviewed in one-to-one privacy. Fourteen were clients of the Shetland Community Drugs Team (SCDT), ${ }^{3}$ the island drug treatment agency located in Lerwick. Ten hidden users were not receiving any drug treatment, with one hidden user claiming to be prescribed methadone by a general practitioner outside Lerwick. Consequently, hidden users are referred to as non-clients in this article. With respect to the client group, it was intended to include persons who were actively involved in the heroin culture by regularly purchasing and possibly dealing, and thus able to provide deep and wideranging insight into the internal structures of the island heroin scene. Concerning the second group, the aim was to focus specifically on socially integrated and occasional heroin users in order to also gain knowledge of the peripheries of the subculture as well as the social conditions of physically "non-dependent" using patterns. Social integration is understood as involving three conditions: being employed, living in a permanent accommodation, and socializing with numerous persons not using heroin.

Clients were accessed and recruited at the SCDT, and non-clients through extensive social networking and snow-balling techniques (cf. Biernacki and Waldorf 1981). Most nonclients were approached indirectly by a third person who functioned as a type of mediator with the researcher. Some were accessed in informal settings such as at parties, concerts, or in pubs.

Participant characteristics: With eight men and six women the intended equal gender distribution could be approximated in the client group. The non client group consisted of three females and seven males.

Clients: Four of the 14 clients could be categorized as fully socially integrated according to the above given criteria. Two stated to be alternating between employment and unemployment and presently to be unemployed, and eight to be unemployed. With 11, the majority reported permanent housing. The other three were staying in temporary accommodations. Twelve confirmed current use of heroin, with one person to be exclusively smoking. The remaining 10 stated to be primarily injecting heavily and to develop physical dependencies to the opiate whenever heroin was sufficiently available to them. Two reported 
Community-Mindedness: Protection against Crime in the Context of Illicit Drug Cultures? Stallwitz

heavy and habitual patterns of smoking and injecting use, respectively, but to have not used for several weeks and months.

Non-clients and occasional users: With respect to social integration, six of the 10 interviewees of this group completely corresponded to the above given criteria, two could be located at the margins of this group, and one reported being unemployed and dealing. One man objected to revealing any personal information about himself that was not related to his drug use. All others confirmed permanent housing, mainly rented flats or houses.

Within the group of non-clients, occasional users are categorized as a separate subgroup. This further subdivision is explicable in terms of individual, social, and heroin using circumstances, which differ significantly from all other participants. Therefore, occasionally using non-clients are referred to as occasional users and all others from this group merely as non-clients, indicating that the latter engage in alternating patterns of drug use with at least one brief period of physical heroin dependence. Many non-clients describe their personal heroin consumption patterns as alternating between heavy habitual, less frequent, and even occasional use. In comparison, occasional users include only persons with physically non-dependent use which does not interfere with any important professional or private parts of their life. Criterion for all non-clients including occasional users was to have used heroin at least five times in the past three years and at least 10 times in their lives (additional details with respect to participants' histories and current patterns of heroin use can be derived from Appendix 1).

Local professionals: In order to obtain perspectives alternative to the user interviews and thus increase the credibility of the results, an additional 11 one-to-one and focus group interviews with a wide range of Lerwick-based professionals were conducted. Interviewed professionals included the managers and members of staff of the SCDT and the Youth Information Service, a drugs politician, a methadone prescribing general practitioner, a methadone dispensing and needle exchanging pharmacist, a policeman from the island drug squad, journalists of the local newspaper, and members of the staff from the homeless person's team. These results have been published in a separate article (Stallwitz2007).

\section{Research Instrument}

Comprehensive semi-structured interview guidelines were employed (for a full copy see Appendix 2). Areas relevant to the research questions were covered, including 1. personal details, 2. personal drug using history, 3. current patterns of drug use, 4. personal meaning of heroin and heroin use, 5. the heroin scene in Shetland, 6. heroin use and identity, and 7. control over personal heroin use. Further five to seven sub-points were subordinated to each overriding theme.

With respect to the already mentioned emergent interview design, some of the original interview sub-themes were omitted and others later included. Some topics moved from the back- to the foreground as they repeatedly received pronounced attention by the interviewed persons. For example, number 4 (personal meaning of heroin use) lost some of its original 
significance, whereas 5. (the heroin scene in Shetland) seemed to be of specific importance for virtually all interviewees and therefore became a matter of particular interest.

\section{Interview Setting}

Participants were interviewed in strict one-to-one privacy and an atmosphere as close to a natural conversation as possible. For client interviews a room in the SCDT's administrative premises was booked at times when the building was empty. On the one hand, to most clients this room was familiar and on the other hand, it provided confidentiality. One client was interviewed in a counselling room of the SCDT treatment building. Non-client users were according to their preferences either also interviewed in this room or alternatively at their own homes.

\section{Data Collection and Interview Conditions}

The interviews were recorded with an analogue recording and transcription machine and lasted between 42 and 123 minutes. Before participants were interviewed, their informed consent to record the interview and further utilize the anonymized interview data was obtained. Interviewees were explicitly confirmed of confidentiality and encouraged to solely reply to questions they felt comfortable with and to immediately end the interview in case of any discomfort. Information sheets with a brief summary of the purpose and procedure of the research project were handed to respondents before their interview.

Examining a highly stigmatized behavior in a small, close-knit community involved various complications. In particular, non-clients appeared wary with respect to taking the social risk of talking to an unknown person about their heroin use and even being recorded. As a consequence, numerous potential non-client interviewees rejected the request for an interview.

\section{Provisions for Trustworthiness}

To provide a context for the interview data and to increase their credibility further data were collected. These include relevant epidemiological data from the Scottish Drug Misuse Database, the police and other criminal justice agencies, newspaper articles and ethnographic data. Frequent exchange with other drugs researchers during data collection and the complete research process was aimed at reducing the single researcher bias.

\section{Confidentiality and Ethical Considerations}

In order to protect participants' anonymity regarding a highly stigmatized behavior in a small, socially close island community, specific endeavors were undertaken not to create any risk of people being identified as using heroin. Names, places, and other personal details were changed or distorted as to guarantee interviewees' anonymity. 
Community-Mindedness: Protection against Crime in the Context of Illicit Drug Cultures? Stallwitz

\section{Data Analysis}

The 24 user interviews were transcribed and analyzed according to the principles of grounded theory (Strauss and Corbin 1998). This method was originally developed by Glaser and Strauss in the context of studies concerned with medical sociology (1967). It involves the emergence of recurrent themes through inductive-deductive analysis and certain coding procedures. On this basis categories and subcategories are developed of which typically one stands out as a central category relating to and organizing all other categories. In this study community-mindedness constituted the so-called 'core category'. As a final step in the analytical process, a theoretical model is generated that explains all essential interactions, dynamics, and coherences characteristic of the phenomenon under examination. Thus, the theory that emerges is grounded in the social activity it intends to explain (Taylor and Bogdan 1998).

In the subsequent interview analysis, statements by clients are indicated by $\mathrm{C}$, nonclients by $\mathrm{N}$, occasional users by $\mathrm{O}$, and the researcher (the author) by $\mathrm{R}$. To protect interviewees' anonymity and avoid disclosing personal details that could identify them, sometimes no further information is provided. Direct and indirect interview quotations are cited by first providing the interviewee's name and then in square brackets from the transcripts, both the page number(s) and the line number(s), e.g. [4, 39-42] from the group.

Since all interviews were conducted in summer 2004, this period of time constitutes the temporal basis for interviewees representing their "now". Future and past developments are also defined against this "now". Conclusions on grounds of other data sources are each time indicated.

\section{Interview Analysis and Interpretation}

\section{Shetland's Location-Specific Socio-Geographic Characteristics}

Small size, geographic isolation, and socio-economic wealth: Interviewees generally depict Shetland as characterized by extremely low rates of crime and social deprivation when compared to the rest of Scotland. ${ }^{4,5}$ Typically, the island's relative wealth and high levels of employment $^{6}$ are often referred to when making these comparisons to the mainland. Many of the regular, dependent heroin users are reported to finance their daily drug consumption on the basis of paid work. People with heroin habits on the urban mainland of Britain are by far more readily associated with begging and stealing. One urban long-term user portrays Shetland heroin users as being socio-economically privileged.

Robin (C): They're livin' in a bubble up here. The Shetlanders don' really know, I don't think, they really know how lucky they are to have the way a' life tha' they've go'. They have a drug problem, I know tha', I've been in the circle wi' the drug problem, bu' the crime isnae up here, you know? People usually work up here to pay for their drug problem. You know? Whereas on the mainland people steal to feed their habi' whereas up here people work. [7, 32-37] 
Another urban long-term user points out that there is crime in Shetland, such as shoplifting and break-ins, but to a significantly smaller extent and that many Shetlanders "keep their habits going" through full-time employment [Mark, C, 1, 43 - 2, 7]. The longterm using Shetlander Angus (N) also stresses the significance of the fortunate socioeconomic situation in Shetland that allows a lot of dependent users to pay for their drug consumption with their regular earnings [11,505-51, 12, 1-8]. Another employed client gives a description of his personal user group, in which he and his five friends between their mid20s and mid-40s all finance their drug use with their wages [Oscar, 2, 39-49].

Social stigma, social cost, and secrecy: When explaining the low local rates of acquisitive crime, interviewees argue that generally drug users, including dependent and unemployed persons, do not face the same socio-economic pressure to commit crimes as they do in urban Britain. Furthermore, they explain that the island's close-knit community, geographic isolation, and small size lead to high levels of social control which in turn deters most people from engaging in criminal endeavor. With everyone knowing each other and the high social visibility of behavior, participants describe the social stigma attached to heroin by the general public as specifically influential in discouraging people from activities communally regarded as deviant [e.g. Oliver, O, 5, 10-12].

Overall, interviewees seem to share the perception that social sanctions following deviant demeanor are particularly severe and far-reaching on a small, socially narrow island. The stigma's impact is stated to be intensified again in places outside the town of Lerwick [e.g. Mona, C, 7, 23-50]. Feared social sanctions include social exclusion, job loss, and being the subject of gossip [e.g. Christian, O, 10, 35-44; Oliver, O, 22, $34-23,15$ ].

The island heroin users and dealers are described as therefore tending to act very secretively concerning their involvement with the stigmatized substance. Consequently, the surrounding heroin subculture exists relatively unnoticeable to uninformed persons and the general public [e.g. Cathy, C, 1,44-2,2; Mona, C, 7, 49-50]. Employed users seem to be specifically careful not to attract attention to their illegal activities and thereby putting their job at risk, as explicated by one working long-term user [Angus, N, 12, 8-10] . ${ }^{7}$

Anticipated social cost as treatment barrier and infection risk factor: For a substantial number of users, again particularly working persons, the anticipation of social cost also appears to function as a treatment barrier. Two personal examples are provided by the employed Shetland men Ben and Philip, who state that they fear if they frequented the drug service in Lerwick, their employers or other people might find out about their heroin use [Ben, N, 15, 36-51; Philip, N, 6, 32-39]. Many in need of professional assistance "won't go near the place [Shetland Community Drugs Team in Lerwick], just for the stigma," maintains the Shetland woman and client Claire [3, 44-47].

Ostracism seems not only feared on parts of the general public but also the drug using community itself. Several participants tell of various occurrences they had observed where this fear had become apparent. One urban user emphasizes his amazement about the high number of hepatitis $\mathrm{C}$ positive users in Shetland and the often pronounced effort he had witnessed of infected people to conceal their condition. 
Community-Mindedness: Protection against Crime in the Context of Illicit Drug Cultures? Stallwitz

Robin (C): I mean, the amount o' people on this island wi' hep C is unbelievable!

R: Is it?

Robin: Oh! I' REALLY is!! An' the amount o' people tha's probably walkin' abou' wi' tha' an' don' know. Because [...] the amount o' people tha' came up an' says, Oh, Robin, I've go' i' bu' I don' tell anybody." Tha' was quite shockin' actually the amount o' people tha' told me tha' had it an' yet they wouldnae tell other people on the island.

R: Because they've, um, all been sharing?

Robin: Ay-ay. Because they've feared [...] tha' they would be singled ou', you know? Soo they chose to no' to. [...] If you're in somebody's hoose an' you're gonna use, [...] you infect somebody jus' because you don' want them to know [...]. I had a boy who just started injectin' in the last five months in somebody's hoose an' I was talkin' to him an' he was tellin' me abou' how he collects everybody's filters on the island. An' I was like...Have you never heard of hepatitis C?!" An' he's like, What's that?" So when I explained to him wha' hepatitis $\mathrm{C}$ was his face went white an' he just collapsed intae a chair. An' he told me a number o' things an' some o' the people he used wi' an' he asked, What percentage, you reckon, tha' I was havin' hepatits C?” An' I was, Och, 90/95\% chance you've ge' hepatitis. Because of some of the people tha' you have wi' an' shared the wa' 'er an' the spoons an' the filters." [11-12, 41-49]

Overall, interview accounts convey the impression that the more a person fears to lose, the more secretive they will handle their stigmatized behavior. The underlying motivation in all cases seems to be avoidance of exclusion and loss of social status either with regard to the general public (or specific parts) or the subculture itself (or specific parts).

Relativization of the stigma's power: According to other interview statements, however, the impression is created that the expectation of total and lasting social exclusion may in part be collectively constructed and shared rather than entirely rooted in actual facts. Reports are provided of employers who still employed people although they had been reported in the local newspaper for using or even dealing heroin. Several interviewees contribute personal examples. One male non-client describes in detail the important role of his job in his ability to maintain a psycho-socially stable life [Angus, N, 15, 28-46]. A further instance is given by an occasional user, who had been caught by the police with heroin, which consequentially was reported in the local newspaper. As a result, she had experienced some ostracism but also the possibility of 'a second chance'. For example, after people in her neighborhood had seen her "behaving normally" she could "reinstall herself" and carry on with a normal life including education and work. 
I (O): [...] My name was in the paper an' all the old ladies stopped speakin' to me in the street.

R: Only the old ladies or other people

I: [...] I' was a lo'a people stopped talkin' to me.

R: You you said that that changed again?

I: Yeah. They see me out in my garden. they see me, you kno' doin' normal things an' think I'm okay.

R: Hm-m. And they started speaking to you again?

I: Yes. There's a couple that we've never got back to where we were. Bu' you've gotta pay a price, haven't you? - Hm-m. Hm-m - Bu' I thought this is gonna stop me goin' on to do my diploma. An', ah, I applied, I go' an interview, $[\ldots]$ an' it was only then tha' I was able tae say tae the lecturers, you kno', 'I got busted for heroin'. An' I thought I'd blown i'. I'm no' gonna ge' in. An' then I go' a letter abou' two weeks later sayin' a go' a place an' I had to complete a disposure form for them. So here we go. [13, 19-43]

The conclusion reached from these interviews is that social stigmatization can exert a great influence in a small, remote community such as Shetland. However, its power may be less absolute as anticipated by many.

\section{Financing Drug Use and Drug Related Crime}

Dealing as means of financing one's drug habit: Some interviewees explained that due to limited criminal opportunities, unemployed dependent users receiving social welfare money (benefits) often adjust their using pattern to their financial realities. Personal examples are provided by the mainlander Gerry (C) [13, 41-43] and the Shetlander Rick (C) [12, 2732]. Both clients state to restrict the extent of their respective drug intake to the financial remainder after having paid for electricity and food.

Yet, both users also claim to be part of the island heroin scene's central dealing network [Gerry, C, 11, 40-43; Rick, C, 6, 24-30]. Generally, interviewees depict dealing as a criminal option which can be performed in a much more hidden and less noticeable way than, for example, theft, robbery, and burglary. The long-using mainlander Mark (C) argues that apart from working, dealing constitutes the only feasible way to finance a drug habit in Shetland. The occasional user Oliver, like others, underlines this argument by pointing out the significantly higher price for heroin on the Shetland Islands compared to urban Britain - about $100 \mathrm{GBP}$ for 1 gram that could be obtained for 50 or 60 GBP in cities such as Edinburgh or London [9, 5-12]. 
Community-Mindedness: Protection against Crime in the Context of Illicit Drug Cultures? Stallwitz

Mark (C): [...] The world's different from doon the road! In many ways, man. Food, clothes, basic things is dearer up here - for one. Just to live is maer expensive. Never mind getting' a drug habit. If you're getting' a drug habit up here, if you're no' workin', man, pphh! It's sshhi'! You know, it's no like tha' doon the road [on the British mainland]. Doon the road, I mean, I wake up in the mornin', [...] go ou' for shopliftin', make myself 100 quid in half or an hour, back haem an' go' a scored bag in my hand, you know? Up here, man, you cannae dae this kinna thing. You know, it's it's hard. If you've no' go', if you've no' go' money comin' in every week, right, like, ah, a wage, it's SHIT to keep a drug habit. Unless you're daein' drugs, sellin' drugs then, yeah. Bu' it's so shit up here. [4-5, 51-13]

A similar viewpoint is confirmed by others, such as one heavily and regularly using Shetland man, who emphasizes that due to the small size of the island any other crime but dealing is "nae very bright" [Duncan, N, 8, 46-48]. Interestingly, incoming urban users tend to describe, like Mark did above, how previously on the mainland they readily would have committed crimes to finance their drug habits. In Shetland, however, they learned to adjust to the local social structures by adapting drug-related behaviors to the island context. In the section after the next -- Adjusting urban behavior to the social reality of the Shetland heroin scene -- this process of social learning and adaptation will be exemplified with the account of the urban incomer Robin.

Prostitution:_According to Shetland's social conditions as depicted above, acquisitive crimes, such as robbery and shoplifting, are usually not regarded as an economic long-term possibility to finance one's drug use [cf. Gerry, C, 14, 18-21]. Mostly, this also applies to prostitution. Nonetheless, in a very limited and socially inconspicuous way, exchanging sex for drugs appears to take place on the island, as indicated by a few participants.

Below Claire (C) gives details of her observations regarding prostitution in Shetland and how some female users act as so called "skag slags".

Claire (C): [...] There's a few girls tha' have worked, tha' I know tha' have.

R: Is that only on the mainland or up here as well?

Claire: Yeah, there's a couple of girls up here, tha' used tae. There is this girl called Mary. [...] Not so much as a, I mean, prostitution as standing on street corners, but... making arrangements for certain men, you know? Uum,... she used to go on boats years ago, she used to go round the fishing boats an' that. But nothin', I mean, you wouldn' get people standin' at street corners, that's all I know anyway, I can't think of anyone else.

R: Was that then drug, drug, ah, related prostitution or nothing to do with drugs? 
Claire: Oh, here, yeah, tha' would be drug related, yeah. Before I don't know, about the boat thing. But then they could have just been promiscuous, as you say. This girl I know, yeah, she, tha' was drug related. I mean, that's the usual, that's the usual kind of, what's used to be termed as "skag slag", you know, people tha' sleep with... drug dealers. Yeah, that's goin' on up here, but only limited to maybe two or three females, I would think. I mean, it's mainly men up here, there's no' many women with... heroin habits as such. [3, 16-41]

One woman speaks about her personal experiences of being intimately associated with different dealers in order to obtain her daily drug supply [C, 5, 11-18].

The long-term user Gordon (C) speaks about a small number of women who prostituted themselves to finance alcohol habits. However, when they began consuming heroin intravenously, they discontinued because they were ashamed of their injection marks [11, 46$51,12,7]$. One intravenously using Shetland woman tells about her years as a drug using working girl in a British city. Although she carried on using heroin when she returned to Shetland, due to the island's lack of anonymity, prostitution would not have been an option for her to finance her drugs.

As with respect to criminal behavior in general, the Shetland Islands' small size and social fabric might not offer the conditions that would allow for prostitution being perceived as a business. Moreover, intravenous drug users would take the risk of being detected with two forms of socially unacceptable conduct. Hence, for most people the lack of anonymity and fear of social sanctions seem to result in the anticipation of a higher cost than benefit. Hence, criminal conduct is broadly discouraged.

Overall, interview accounts lead to the impression that in Shetland the majority of dependent drug users, as of people in general, adjust their behavior to the social norms on the island. With regard to financing drug use, for most this implies restricting oneself to employed work, social benefits, and selling drugs. In addition, helping out each other seems to be of crucial relevance in this context as will now be illuminated.

\section{Community-Mindedness and the Shetland Heroin Scene Mentality}

Bouncing off each other: However, the location-specific factors are not only portrayed as intensifying social control and sanctions, but also as encouraging pro-social, communal behaviors. This seems to apply equally to the general island community and the local drug culture. Within the "very cliquey" [Angus, N, 1, 44 -1,45], close-knit social network of the heroin scene people usually do not have to beg [or steal], but can borrow money from friends [Gerry, C, 6, 13-14]. The mention of a communal, caring spirit amongst islanders reoccurs throughout the interviews. Mona (C), for example, explicitly associates Shetland's low crime rates with people, including heroin users, tending to care for each other.

Mona (C): The price tha' i' costs, it's really expensive, so the circles tha' you are in, because i' is Shetland a lo' o' people bounce off each other an' if 
Community-Mindedness: Protection against Crime in the Context of Illicit Drug Cultures? Stallwitz

you go' a bit then you might be offerin' i' to your friends or somebody who's a close friend or they might give you a bit an' you end up bouncin' off each other an' kinna all helpin' each other ou', to a certain degree. An' I think, that's why there's probably no' so much crime up here. People know tha' you cannae ge' away wi' house breakin' an' all tha' up here, so there's no point in doin' i' unless you wanna go tae jail. [7, 12-21]

Apart from "bouncing off each other" (taking turns in aiding one another), buying "on tick" (on credit) is also mentioned as Shetland typical. Yet, to what extent such options are available to an individual depends on how well someone is socially connected within the drug using community [e.g. Lilly, N, 12, 20 - 42].

One female client maintains that due to the lack of anonymity and therefore criminal opportunities, a lot of heroin users also build up debts when they are unable to finance their drug consumption [Claire, 4, 8-17]. Another interviewee describes how in this way they became indebted to a dealer, whereas, when they lived in a British city they would engage in illegal activities to support their habit.

Adjusting urban behavior to the social reality of the Shetland heroin scene: As has already been pointed out, most people in Shetland - islanders and incomers alike - seem to adapt to the local social standards and behavioral norms. In the following, an example is given of the preparedness and abilities of urban users to adapt prior city manners to the specific social situation of the Shetland Islands. In the context of the various urban heroin subcultures Robin, quoted below, had previously been involved in, criminal and violent conduct had both been part of his typical behavioral repertoire. Within the Shetland heroin scene, however, he describes such demeanor as not only depreciated but also unnecessary - drug trade related interactions usually occur without the presence of guns. Moreover, he explains, that he wants to respond to the respectful and supportive treatment he hitherto has experienced in Shetland in an appropriate style. Within the scope of urban anonymity, impersonal crimes seem much more acceptable for him than in a social setting where he knows the people he would harm. This apparently would conflict with his self-image and personal value system.

R: And would you say that there are certain things you would have done on the mainland you wouldn't do up here?

Robin (C): Oh definitely! Definitely.

\section{R: Like what?}

Robin: Aaah, breakin' intae places, like shops, you know? Like on the mainland it's multinational companies, in Shetland it's like family businesses, you know? Sooo, that's just as bad as breakin' into their house. You know? 'Cos, 'cos they're no multinationals, so therefore you're hurtin' the people personally. Bu' on the mainland I, second nature was, a lo' o' the way I kept my drug habi' was to break intae factories. Tha' was the reason why I was out ootta [British city]. [...] I knew how to ge' intae so many 
safes, [...] So, I mean, like shop-lifitin', tha's somethin' I wouldnae do in Shetland either. Bu' on the mainland, aye, definitely, no' a problem. tha' an'

R: What else? Are there other things?

Robin: Aah, I wouldnae, I wouldnae bring drugs onto this island.

R: Why not?

Robin: Aaah, this island's been good to me, ah, on the mainland, aah... I'd done a lo' o' bad things when I was young. I was a very angry boy an' I used to carry weapons 24/7. Aah, I'd been shot, I'd been slashed, I'd been battered with baseball bats aaand I have done the same thing to other people. $\mathrm{Bu}$ ' when I came up here for the first five weeks I still had the mainland mentality, you know? An' I still carried everywhere I went a double edged dagger, was always my preferred tool. [...] 'Cos it's no' like on the mainland up here. My heid's no' in hinges. I don't need eyes in the back o' my heid." You know? Like pubs on the mainland, if I'm sittin' in a pub on the mainland I'm sittin' wi' my back part against the wall an' I'm sittin' where I can see who's comin' in the door. You know, it's, whereas up here I can sit on a stool wi' my back to the door, you know? I'm no' waitin' on somebody to come in an' runnin' a shoo' through me or a bullet through the back o' my heid. $[\ldots][6,1-7,3]$

The interviewed sample includes a number of heroin users who previously lived in cities of Great Britain, such as Robin or Mark cited above, who report regular commitment of various crimes in urban contexts prior to moving to the Shetland Islands. Generally they state that they adjusted their manners to the social norms and reality of the island setting. Especially accounts of this sort give rise to the assumption that criminal behavior including acquisitive crime is performed in accordance to a collective and consequently subjective perception of cost and benefit resultant from this behavior. Collective in this relation refers to the conditions of the cultural and social setting which is also subject to historical change as will be illustrated below.

Community-mindedness amongst Shetland dealers and user: Repeatedly interviewees characterize the style of social interaction amongst islanders in general, including heroin users, in terms of a spirit of community-mindedness. Especially in comparison to drug cultures in urban areas interviewees had encountered on the British mainland, such a community spirit is regarded as a central differentiator. The association of community-mindedness and localityspecific differences in the context of crime and deviance becomes apparent.

The causal conditions of the community-minded spirit appear to lie in Shetland's small size and population, as well as its geographic isolation. Together these factors are presented as leading to the island's close-knit network of social relations that encourages care and reprimand both within the general community and the heroin scene. In this context, the inclusion of perceived insiders and the exclusion of perceived outsiders play a crucial role. 
People acting in a way that is perceived as deviant by a specific group, e.g. a certain section of the general public or of the heroin scene, may be sanctioned for their behavior in form of exclusion or gossiping. At the centre of the communal spirit seems to lie "feeling and acting as part of an exclusive group open to specific select members rather than to everyone" (Stallwitz 2012, p. $174^{8}$ ). Hence, a community-minded spirit might not be a social quality unique to remote non-metropolitan locations such as the Shetland Islands. Under certain conditions, community-mindedness is likely to be generated in any socio-geographic setting including metropolitan districts. This assumption will be taken up again in the discussion section, where it will be illuminated further in relation to ethnographic research of urban heroin cultures.

Another particular feature of the Shetland heroin scene interviewees refer to frequently constitutes the above mentioned tendency to create "cliquey" social networks. Cliqueyness as described by interviewees manifests itself in numerous "smaller and bigger sections and subsections, groups and groupings and circles, and sub-circles" (Stallwitz 2012, 175). This characteristic seems to be associated with closeness of social relations which again tends to be found most frequently in cultures and subcultures in rural, especially remote locations.

\section{A Changing Trend within the Island Heroin Scene: Commercialization and Urbanization}

When compared to urban drug cultures, the island heroin scene is typically characterized as decisively less problematic with respect to the occurrence of drug use related crime, violence, and social pauperization. Still, as already pointed out by Robin above, heroin use in Shetland tends to be considered "a problem" [e.g. Robin, C, 7, 34-37; Philip, N, 13, 37-40; James, 2, 28-48]. Drug-related problematic phenomena seem to occur to a considerably less noticeable degree than in certain urban areas, nonetheless they apparently occur and, as stated by virtually all interviewees, do so increasingly.

A trend of incremental changes is described that set in a few years after the turn of the century [cf. Gordon, C, 2, 34; Duncan, N, 10, 31-33; Gerry, C, 12, 33; Angus, N, 11, 35-44]. Alterations entail an overall spread and growth of heroin use in general and heavy, intravenous and risky using patterns in specific; large increases in unemployment among young females ${ }^{9}$ and also diverse kinds of users, and occurrences of violent and criminal behavior [Duncan, N, 10, 31-47; Rick, C, 5, 12-15; Kay, O, 2, 25-30; Mark, C, 3, 47 - 4, 4]. In citations representative of reflecting the illustrated expansion of the heroin subculture, interviewees speak of "an explosion into a major scene" [Gerry, C, 12, 32-34], of "floodgates opened" [Rick, C, 9, 17-18], and the offer of "heroin in bulk" [Kay, O, 1, 13-19] concerning the increased amounts of the opiate turned over on the island drug market.

Several participants compare the transitions within the island subculture with developments they witnessed in urban Scotland 10 to 15 years earlier. Here a general shift had taken place from small, strictly organized, socially oriented, and exclusive underground scenes to commercialized, comparatively anonymous cultures without clear boundaries.

R: Can you describe how it has changed in the last few years? 


\begin{abstract}
Angus: Well, it's just more an' more people tha' have go' into it. I, I see it very very similar to when I lived in Aberdeen, when I first started to ge' into heroin in Aberdeen. I mean, i' was like quite a small group to begin with an' it just grew an' grew. It was just like an explosion, you know, ken. I' was just everyone started to ge' into it an' the crack came on the go as well. Bu' crack has never really taken off in Shetland - yet. [11, 35-44]
\end{abstract}

With the parallel of the Scottish 'heroin explosion' having taken place in the late 1980s, the conclusion seems plausible that the transition to more conspicuous use on the Shetland Islands reflects a delayed drug trend that before had been observable not only in Scottish cities, but globally in many urban areas.

Even though the use of heroin in Shetland apparently had increased dramatically between the beginning of the millennium and 2010 (also see ISD Scotland 2010), the island crime rates still belong to the lowest in Scotland (HIE $2011^{10}$ ).

\title{
Causal Conditions Initiating Commercial, Urban, and Criminal Tendencies
}

Global drug trend, preceding rave era, and "prison connection": Causal conditions involved in the initiation of the processes of commercialization and urbanization named in this respect embrace various global and local factors. These include the already mentioned global heroin trend reaching Shetland, the prior rave era that "normalized" illegal drug use to a relative degree (e.g. Ben, N, 1, 15 - 2, 28]; Patrick, C, 3, 34-43), a rising influx of incoming users from British cities importing urban norms and manners, ${ }^{11}$ and the market take-over by two clearly commercially oriented dealers. Another powerful influence which several interviewed users refer to specifically in relation to the above indicated tendencies of criminalization constitutes the "prison connection". This term mirrors the dynamics associated with the increasing rate of incarcerated Shetland heroin dealers due to the expanding subculture and intensified police activity.

R: No, but you were talking about those people coming in to Shetland.

Duncan: Right. There's been, i' is really been a prison connection tha' started. More an' more people ge' sent down to prison as well, from here. Locals, tha' were sent to jail for their drug offences. Aah, there's never assaults, robberies, anythin' like tha', because it's it's nae very bright. It's all drugs, it's always drugs things. [8, 41-48]

Prison apparently represents an environment potentially functioning like a 'contact forum' or 'criminal school': Here Shetland dealers are provided with the opportunities to connect with influential dealers and professionalize their criminal skills. After release from the institution these contacts can and seemingly have been developed and utilized. A number of interviewees speak of the fortified police intervention as the primary reason responsible for the criminal inclinations that had begun to emerge within the island heroin subculture [e.g. Rick, C, 5, 12-15]. 
Community-Mindedness: Protection against Crime in the Context of Illicit Drug Cultures? Stallwitz

Directly related to the "prison connection" seems to be the "Liverpool connection" which various interviewed heroin users mention when explaining the causes of the sudden and rapid escalation of heroin use on the Shetland Islands [e.g. Gordon, C, 4, 46]. According to the accounts of those participants who state to have comprehensive knowledge and understanding of the internal structure of the island heroin culture, the enterprise of the new commercial dealers was embedded in an organized supply system based on the British mainland. Apparently, the two dealers obtained a large part of the heroin they sold in Shetland from a major supply network in Liverpool [e.g. Rick, C, 9, 2-19; Christian, O, 13, 43-51]. Newspaper articles confirm these statements, as for example The Guardian on 23 April 2008 in a report about the death of a 17-year old Shetland girl after a heroin overdose (also see The Times Online 18 August, 2007):

[...] Despite its prosperity, remoteness from Britain's cities and low crime rates, heroin had taken hold, couriered in by drugs gangs from Liverpool and Glasgow. The case exposed surging rates of heroin abuse among under-25s. [...]

The trend towards heroin use reflected in rising numbers of (young) heroin users (also see DrugLink, 2010) that had started to become apparent just after the turn of the century seemingly continued until approximately 2011 (CADSS 2012).

Changing value system: “Junkie manners" becoming more acceptable: According to interviewee accounts, for about two decades since the early days of the Shetland heroin scene in the late 1970s, use and trade related values, norms, and manners had mirrored a strong sense of community-mindedness and control [cf. Oliver, O, 3, 1-6; Kay, O, 2, 1-10; 6, 6-18]. Consequently, behaviors such as dealing for profit, excessive, risky and open use, and criminal and violent demeanors had been regarded and treated as unacceptable and deviant and thus had been counteracted and sanctioned by dealers and influential users within the subculture itself.

One urban long-term user explains how the main dealer before the market takeover by the already mentioned commercially oriented dealers in the beginning of the millennium secured stable control over the heroin scene by restricting the amounts of heroin on the Shetland market.

Gerry (C): [...] When, when [Peter] was doin' it [...] there would be spells where we would go go through a bi' o' a drought. Sometimes. six to eight weeks sometimes. So i' was kinna, in a way i' was good, because everybody got back into a little break. An', ah, it caused problems for some people. Heavier users were kinda sufferin' for the six to eight weeks kinda thing. Bu' at the same time I 'ink in a way it was, I 'ink in a way i' was his way of tryin' to keep people, tryin' to keep people's addictions from spirallin' out of control. The amount o' people wi' problematic addictions, I 'ink, he did try to keep a bi' of a lid on for tha' reason. He didn't want to be the one that was to,.. to blame kinda thing for a, for a heroin epidemic in Shetland. [3,

\section{5-24]}


In mutual dependence with the above outlined behavioral changes and associated causal influences, the overall scene's underlying value system had also begun to undergo a process of incisive transitions. As a result, formerly strictly sanctioned behaviors became increasingly more tolerable and thus prevalent and prominent. As one occasionally using Shetland man phrased it, the heroin scene changed from "sociable" to "more and more sordid" [Christian, 10, 30-32]. The following interview extract depicts a shift from a community-minded exclusive group to an affiliation based on self-serving utility.

Christian (O): [...] Mainly because there's more an' more people tha' that like people's friends and family getting' into it. An' then there's people startin' to inject it an', ah, it's getting' more an' more sordid. It used to be kinna a reasonably sociable thing. But noo it's like like really sordid. From my opinion anyway.

R: Can you describe that a bit more? How it used to be more sociable...

Christian: Well, it used to be, ah, poeple phonin' up 'Hey! Come on, let's ge' a bi' of fuckin' smack!' - 'Oh bloody hell! It's been fuckin' ages!' A few people would turn up at this guy's hoose who's the seller. In tha' respect you're jus' like liable: 'Fuckin' hell, oh, oh, oh!' Bu' i' was a treat. An', ah, it brought people together, if you want, for a be' 'er thing. Ah, because i' wasn't regular, people kinna looked forward to it. It was like, ah, 'Fuckin' excellent!', ken? It, you sat aroon' wi' like a few close friends. Bu' you'd never really tell anybody. It was a completely secretive thing, ken? Bu' noo it's it's every month an' it started to turn to a market itself an' you can get it a regular day an', ah, people are also rippin' each other off an' backbitin' an' cuttin' i' up wi' shit an' takin' their own little cut an' things an' sellin' it on an' creatin' bad feelin'. An' tha' kinna, there's lo' o', yeah, bad feelin' in the scene noo, whereas before it wasn't really a scene. An' i' was every now an' again tha' somebody came across wi' smack an' it'd be a kinna o' thump thing. Bu' noo it's far from tha'. It turned pretty serious, as far as I'm concerned. $[\mathbf{1 0 , 3 0 - 5 0 ]}$

Interview quotations give rise to the assumption that beforehand social relations had been instructed predominantly by communally, pro-socially oriented norms. Now a certain form of a "junkie attitude" had begun to spread considerably throughout the subculture [e.g. Angus, N, 14, 39-52; Christian, O, 8, 9 - 20; Mona, C, 4, 29-34]. In her following argumentation, the occasional user Kay presents the development and expansion of a "junkie mentality" as causally related to the spreading addiction rates. Still, she differentiates between groups and applies this label only to a specific subgroup within the overall heroin scene.

Kay: [...] Bu' I've maybe changed my perceptions. As wha' addictive disease does to the mentality,... to the compassion in in several people. Maybe not everybody. I I resisted the concept of a junkie mentality. But now I see, yup, I can see that there are general behaviours that come wi' the territory. 
Community-Mindedness: Protection against Crime in the Context of Illicit Drug Cultures? Stallwitz

R: You saw that like associated with addicted heroin use? Like this maliciousness?

Kay:... Not in everybody, no. Bu' in a... in a kinna little subculture. Tha' was like doggy dog. 'You do this to me, I do that to you', 'I steal your money - this is okay, because I'm a junkie'. An' Shetland tha's always been a very warm sharin' compassionate place to me. So I've been shocked. [4, 34 - 44]

Similar observations are illustrated by the Shetland woman Mona (C). According to her, certain "people started stealing off each other" and this would never have happened before. She relates behaviors of this kind to the financial pressure of people who previously spent their capital on their drug habit. Associated with these dynamics as well as with the recent upsurge of incoming heroin users and dealers she also regards the increase in drug related crime she states to have noticed [4, 29-34].

Although interviewees generally speak of significantly rising addiction rates, they also convey the impression that the diversity of users had increased simultaneously and the relationship between dependently and occasionally using persons might not have changed fundamentally.

As opposed to the community-minded style of interaction predominant in earlier times, self-serving, opportunist, and even violent manners had started to expand. Simultaneously, with the diminishing of the community-minded spirit, the stringent control rules in accordance to which trade and use of the opiate had been kept both secretive and clearly restricted are pictured as having lost ground. In consequence, so to speak, a door had been opened to individually and socially risky and destructive behaviors, including drug related deaths. ${ }^{12}$ As the occasional long-term user Kay explicates, the scene had lost its 'innocence' and thereby the almost idyllic character of social togetherness that had determined its character for approximately two decades [2, 24-30]. This 'loss of innocence' seems strongly associated with the influence of the organized dealing network in urban Britain, the rapid rise of diverse people getting involved in the subculture, and the intensified police interferences with the scene [e.g. Duncan, N, 12, 42 - 14, 21; Christian, O, 13, 43-51]. In consequence, heroin users' general perception of the opiate seems to have shifted from a treasured, exclusive good to a commercialized article of merchandize. Apart from a process of commercialization, the outlined transitions could also be captured by the terms urbanization and, to a certain extent, criminalization.

\section{Discussion}

The interview analysis has revealed multilayered dynamics determining the developments of an illegal drug subculture in a small, wealthy, and remote island community over time. It could be assumed that small communities by nature exhibit a strong sense of community-mindedness that in turn automatically functions as a protector against criminal and generally destructive inclinations. However, it has been demonstrated that such protective effects depend on the respective cultural, social, and historical circumstances. With respect to 
socio-historical influences, universal forces such as global drug trends seem to strongly impact on the expansion and nature of an illegal drug scene. Concerning the relationship of subculture and the respective wider culture in which it is embedded, a global drug trend could be regarded as reflecting essential aspects of the zeitgeist ${ }^{13}$ characteristic of a certain era.

In which way exactly the global changes in drug production, trafficking and use manifest themselves at an individual location is subject to the site-specific socio-economic, cultural, and geographic dimensions, as well as subcultural conditions at a particular point in time (cf. Structural Model, Appendix 3).

The present investigation provides various concrete examples of significant correlated subcultural and cultural influence factors. Instances representing impacts acting on the subcultural level constitute the "prison connection" and the presumably associated market takeover by profit-oriented dealers as well as the foregoing rave epoch. To the latter, interviewees repeatedly refer to as having caused a relative normalization of drug use within numerous social groups of the Shetland population. In the context of explaining the trend towards heroin use on the British mainland in the mid1990s, the "normalisation hypothesis" has also been put forward by Parker et al. (1998) and Parker (2005). Similar to interviewees from the present investigation, the authors causally associate the significant expansion of heroin use with the preceding rave era as a consequence of which illicit drug use experienced a relative societal normalization.

In the already referred to expert study conducted in Shetland in 2004, different professionals describe a general shift from an originally self-responsibility and activity oriented mentality to a "historically developed dependency culture" in certain social groups (Stallwitz 2007). As one noticeable effect, not to work had become more socially acceptable. Members of the island homeless team again draw parallels to Scotland in general, where a similar shift had been observed in the late 1980s, possibly as a knock-on effect of the welfare state (Stallwitz 2007, p.266). This effect might have been further augmented by the commencing recession of the island economy. Two professionals from the local drug treatment agency SCDT (Shetland Community Drugs Team) made similar statements, including references to the spreading of a "demand culture" and a "negative client state of mind" amongst their clients. Whereas previously they had related the latter primarily to dependently using clients from urban Britain, they associate this attitude now increasingly with Shetland clients also (Stallwitz 2007, p.266).

From a geographical point of view, factors shaping cultures and subcultures can be conceptualized as occurring on a continuum with local at one pole and global at the other and many gradations in between the two categories. From a sociological perspective, influences can act on the micro- or macro-social level, again with numerous nuances connecting the two. The prison connection and market takeover could be regarded as local factors impacting on the island heroin scene from the subcultural and thus micro-social level. The preceding rave could be viewed as occurring on a subcultural, micro-social level, even though its diffusion is worldwide. The generation of a "dependency culture" could be regarded as a global force on the plane of the mainstream culture and therefore has macro-social implications. The 
Community-Mindedness: Protection against Crime in the Context of Illicit Drug Cultures? -

Stallwitz

commencing recession again could be conceptualized as a factor exerting an influence on the plane of local macro-social dynamics. A clear-cut differentiation of local versus global and micro- versus macro-social is solely a theoretical approximation of the highly complex interrelated causal associations shaping culture and subculture.

\section{Developments and Transformations of Drug Subcultures}

In the preceding section, changes of the Shetland heroin subculture reflective of and initiated by transitions in the wider global and local culture have been outlined. The theory of subcultural evolution designed by Golub, Johnson, and Dunlap (2005) attempts to explicate the interdependent dynamics determining drug eras.

Golub et al. emphasize that the "prevailing drug subcultures and the individuals" social position relative to them define the range of drugs readily available, the symbolic significance of their use, how use can lead to various affiliations, and social consequences for both use and non-use" (cf. Hammersley, Jenkins and Reid 2001). Drug eras are typified by specific clusters of values, norms, rules, symbols (also see 'symbolic interactionism' according to Mead 1956; Blumer 1969), behaviors, and shared realities.

Golub et al. identified four different phases drug eras typically pass through in their course of evolution:

1. Incubation phase: A sub-population begins using a new drug.

2. Expansion phase: The drug is introduced to wider sub-groups of users with an individually varying susceptibility.

3. Plateau phase: Most susceptible persons have now taken up using and consumption is temporarily wide-spread.

4. Decline phase: Using rates decrease as the general acceptability of the drug decreases. Nonetheless, overall drug consumption often endures for many years as some users continue their use. Thus, drug eras often overlap (as cited in Stallwitz 2012, pp. 347348).

Drug eras represent social phenomena and are broadly subject to the respective sociocultural and geographic 'setting' (cf. Zinberg 1984). Golub et al. also point to the causal significance of historical events in affecting the emergence and transformation of subcultures in the course of time. Of historical relevance to the initiation of the Shetland heroin scene, interviewees repeatedly refer to the implementation of the oil terminal Sullom Voe in the North of the island in the late 1970s. Concerning the subculture's expansion and partial destigmatization, the rave era appears to be of historical relevance. The development of a "dependency culture" (Stallwitz 2007) could be regarded as specifically relevant in the transitions of the subcultural mentality over time.

The precise path a subculture will take in the future, including the extent of its acceptance by the wider culture, relies on the degree to which people persistently adopt it and 
its behavioral norms (Golub et al 2005). This way, the emergence, transformation, and cessation of drug subcultures are modulated. Novel subcultures form as a consequence of people adapting existing cultural elements to their respective situation. As an obvious result, contemporary subcultures differ significantly across locations and over time (cf. Schulenberg, Maggs \& Hurrelmann 1997). In this context, zeitgeist plays a crucial role: zeitgeist shapes subcultures and subcultures in turn are reflective of zeitgeist.

\section{Trajectories of illicit drug markets}

Challenging the common assumption of illicit drug markets being supply-led, Parker et al. (1998) point to a number of British investigations which propose a demand-orientation. Presumably, the interactive dynamics of an illegal market are subject to both supply and demand-oriented forces (cf. May and Hough 2004). As a result, a sole focus on supply reduction will rarely be successful in minimizing drug using prevalence rates. Besides, drug markets usually hold the capacity of flexible adaptation to the given environmental conditions. Hence, police enforcement as a main or even single intervention cannot be sufficient in controlling drug trade and use (e.g. Coomber 2004; May and Hough 2004). Furthermore, as has already been argued, numerous complexly interlinked socio-cultural, economic, historical, and geographic influences account for a permanent transition. As demonstrated above, such factors embrace locally versus globally and micro-socially versus macro-socially acting influences. Due to their complex and intertwined nature these factors cannot be specified and separated entirely, but functionally approximated by careful and differentiated conceptualization. Considering this highly complex situation, future developments of drug markets can never be predicted with complete reliability (cf. Ager 1999; Coomber 2004; May and Hough 2004).

\section{Community-Mindedness in Heroin Scenes}

As an obvious consequence of the just presented and discussed situation of continuous cultural and subcultural transition, the degree and manifestation of community-mindedness within an illegal drug scene is equally subjected to permanent change. Specific socio-cultural, economic, historical, and geographic influencing factors can be identified that either facilitate or constrain the generation and expansion of a community-minded subcultural spirit. From the historical perspective Golub et al's (2005) model of subcultural evolution, the incubation phase probably provides the socially most exclusive and controlled subcultural situation. The social preconditions might here be most promotive concerning the generation and reinstatement of community-mindedness.

During this period the probability seems highest that subculture is characterized by a restricted number of select persons who perceive the drug as a desirable, precious, and limited good with the capacity to endow feelings of gemeinschaft and togetherness. Thus, members of the subculture are inclined to create various control norms and rules to protect and sustain the subculture and its use and trade-related social structures (also see Grund 1993). This way community-mindedness as a communal spirit is generated and in turn acts as a catalyst concerning the enactment of norms, rules, and sanctions that ensure both a pro-social atmosphere and informal control. 
Community-Mindedness: Protection against Crime in the Context of Illicit Drug Cultures? Stallwitz

In the process of expansion and commercialization, a drug scene faces the risk of losing super-ordinate common ideals and goals, its community-minded spirit, and consequently capacities of informal control. Losing the object of common identification and the capacity to regulate an illegal culture, most likely also causes the diminishing of safeguard mechanisms against criminal tendencies. A reduction in individual identification with the subculture causes subcultural members to lose motivation to protect it and to act socially responsibly towards fellows. Consequently, the scene's overall value system can alter the way that selfish, criminal, and violent manners are no longer restrained but can spread and become influential (also see Grund 199; Lalander 2004). Such transitional processes are reflected in numerous accounts of Shetland interviewees, who describe a "junkie mentality" that had begun to expand and become dominant within the island heroin scene since the beginning of the new millennium. Causal conditions assigned to these transitions by interviewees and local experts (cf. Stallwitz 2007) involved in specifically these change processes encompass a rapid rise in new and diverse users, intensified and invasive police interventions leading to an increase of incarcerated Shetland dealers, and the above described "prison connection"14 (also see Lucchini 1985; Young 1971). The combination of easier and greater heroin availability as a result of the global heroin trend and commercial supply on the island and the described relative shift within the Shetland culture towards a "dependency culture" also seems significant in this connection.

Howard Becker was one of the first to emphasize the importance of social learning (also see Bandura,1977) in the transmission of drug-related norms and values from one generation of users and dealers to the next (1963), and numerous others have followed him (e.g. Lucchini 1985; Young 1971; Zinberg 1984). The "prison connection" probably plays a crucial role in importing crime and violence-related values and manners into the scene. Furthermore, 'urban' and commercial norms and behaviors are likely to be introduced to the subculture by incoming metropolitan users and Shetlanders, who have had contact with city scenes (see "Soothmoother influence" in endnote 11). Besides, through the sudden rise in new user numbers, not all subcultural members can be socialized adequately according to the original community-mindedness, control, and secrecy oriented norms. Hence, a generational shift and transformation of the scene occurred.

The model of subcultural evolution seems to conceptualize and simplify appropriately a typical and recurring pattern in the course of illicit drug scenes. Matching developments are not only reflected by the Shetland heroin scene but by virtually every scene across the world that has been researched in depth and detail. Evidence is, for example, provided by investigations in metropolitan U.S. (Curtis,2003; Spunt 2003), the U.K. (Young 1971), Switzerland (Lucchini 1985), Sweden (Lalander 2004), and the Netherlands (Grund 1993). In terms of urbanity versus rurality, the trendsetting huge metropolis New York presumably constitutes one of the greatest possible contrasts to the small, isolated, and wealthy island of Shetland. Therefore, the strong parallels between the developments of New York heroin scenes and the Shetland scene appear specifically convincing concerning the universality of this evolutionary pattern. 
Besides similarities in developmental patterns, all studies allowing conclusions in this regard suggest that to a greater or lesser degree a community-minded shared spirit had been present in each of the portrayed subcultures, at least at some point in time (cf. Curtis 2003; Grund 1993; Kemmesies 2004; Lalander 2004; McSweeney andTurnbull 2007; Spunt 2003; Warburton, Turnbull and Hough 2005).

Based on his ethnographic investigation of the heroin scene in Rotterdam, Grund maintains that the universal human need for social warmth, interaction, solidarity, and (group) identity achievable through social relations constitutes the fundamental drive in the generation of drug subcultures (1993). Derived from his examination of a scene of heroin users in Norrköping, Sweden, Lalander also identifies the need to get "cosy" as an underlying force in the emergence of a drug subculture (cf. Lalander 2004, pp. 85-110). The descriptions of social closeness by the two authors correspond to the aspect of social care defining communitymindedness. Both authors argue that through the consumption of drugs in a social context this desideratum can be fulfilled. Grund regards essential harmony in interests and "an agreement upon certain recognized values" (cf. Radcliffe-Brown 1952 as cited in Grund 1993, p. 111) as crucial precondition for a subculture holding the potential of this gratification. Due to the subculture's illegal nature, its survival requires a fair amount of secrecy.

However, wide-ranging concealment partially conflicts with the goals of purchasing and consuming drugs, especially amongst persons using habitually and dependently. Besides severe addiction, Grund also regards intrusive police intervention and a lack of structured lives of users as risk factors challenging social coherence and mutual care. Consequentially, high rates of severely dependent and socially un-integrated users endanger communitymindedness, controllability and stability of an illicit drug scene. Such risk factors seem to have exerted an increasing influence on the nature of the Shetland heroin scene after the turn of the century. In situations of this kind, to alleviate emotional and physical human misery (numbing feelings of distress and counteracting withdrawal symptoms) in the short run appears to be more powerful in determining subcultural conduct than pursuing social goals and investing in sustaining the necessary requirements (also see 'higher' and 'lower needs' according to Maslow's 'hierarchy of needs', 1954). Nonetheless, when asked, users and dealers alike typically affirmed a personal preference of socially harmonious, nonviolent subcultural conditions including mutual trust and familiarity between seller and buyer (e.g. May and Hough 2004; McSweeney et al. 2008; also see ONDCP 1997). However, depending on the respective prevailing value system and its related norms, the motivation to gratify 'lower-order' self-serving rather than 'higher-order' social needs might be communally prioritized and dominating (cf. Maslow 1948).

\section{Conclusions: Community-Mindedness in Rural Communities, Drug Subcultures, and Crime}

Various conclusions can be drawn from the complex empirical and theoretical material presented, contrasted, and critically discussed in this article. The aim of this article as formulated at the end of the introduction constitutes the endeavor to portray the complex socio-cultural coherences that embed and determine the extent and noticeable manifestation of 


\section{Community-Mindedness: Protection against Crime in the Context of Illicit Drug Cultures? - Stallwitz}

community-mindedness within a drug culture by the example of the heroin scene on the Shetland Islands. In this context the questions arose how far rurality holds a protective function against criminal and socially destructive tendencies within illegal drug scenes, and if and how far this effect is related to a stronger sense of community-mindedness typically found in rural subcultures. The results of the present study reflect outcomes disseminated in other publications in suggesting significantly lower overall crime rates in non-metropolitan compared to metropolitan areas. However, the individual perception of imminent social cost seems to be decisive factor here. Certain crimes associated with low anticipated social cost may under certain circumstances be even more prevalent in rural than in urban districts. Dealing as an apparently widespread form of acquisitive crime on the Shetland Islands seems to constitute an example here (also see ISD Scotland 2007-2009 ${ }^{15}$ ). Since absolute and expressive figures are impracticable to obtain though, solely an approximation on grounds of the existing statistical (ISD Scotland) and qualitative evidence (Stallwitz 2012; Stallwitz 2007; Stallwitz \& Shewan 2004) is possible.

Synthesizing conclusions from the presented evidence, the impression is created that on balance high levels of community-mindedness foster a social situation inhibiting criminal and other antisocial tendencies. Moreover, rural areas tend to provide a socio-cultural and geographic environment conducive of a communal spirit and the reinforcement of social sanctions in cases of norm violations. Kroeber and Kluckhohn understand culture as essentially consisting of traditional ideas and their attached values (1952, see footnote 1$)$. The general endeavor to maintain social traditions and therefore the adherence to traditional, often community-sustaining values can be assumed to be intensified in locations characterized by social proximity and interpersonal familiarity. Presumably, similar social-psychological mechanisms apply to wider culture as well as to subcultural communities: Persons identifying with their community (cf. Tajfel and Turner $1986^{16}$ ) are motivated to maintain and protect it against threats such as deviant behavior, including crime and violence. Thus communitymindedness is generated and social control encouraged. Social proximity, i.e. social ties, alone without the regulative element of social control is unlikely to have the same protective effect, as has also been found and emphasized by, for example, Morenoff, Sampson, and Raudenbush (2001).

Seemingly, it is not community-mindedness per se which protects against the development and spread of criminal tendencies within a community, but rather the shared belief of what is deviant and how this deviancy should be interpreted. Even though, heroin use and trade appear to be regarded as highly deviant by Shetland's general public, evidence has also been presented proposing a certain social tolerance mirrored in, for example, people still finding employment and not automatically experiencing extensive social exclusion after public identification as involved with this highly stigmatized substance. Although the stigma attached to a drug like heroin tends to be high in most places, whether rural or urban, the associated social threat and cost apparently differ greatly. The degree of social tolerance manifested in the way people treat certain forms of deviant demeanor under specific circumstances and people's expectations of this tolerance appear decisive regarding the actual impact of social stigmatization on an individual's life. 
Community-mindedness and social tolerance might both be relevant socio-cultural features when characterizing the location-specificity of rural as well as urban areas. Both characteristics seem related to various socio-cultural resources that can systematically be strengthened to increase community safety. Specific corresponding approaches and measures are described in Stallwitz (2012, pp. 355-365).

Future research should be conducted with the aim to further specify concepts such as community-mindedness and community-sustaining 'pro-social' norms and their respective furthering and inhibiting conditions as well as associated resources. In this respect, the focus should not only be on communities of the wider culture but also on drug and other deviant subcultures.

Scientifically informed effective programs can be designed in the domains of drug policy and intervention. The focus should here be on the reduction of harm and public nuisance effectively caused by illegal drug cultures, rather than taking a generally repressive approach. In this endeavor, theoretical approaches such as the model of subcultural evolution by Golub et al. (2005) can be very helpful. Additionally, empirical evidence portraying subcultural developments at certain locations, under certain circumstances and at certain points in time are of invaluable significance (e.g. Grund 1993, Curtis 2003, Spunt 2003, Kemmesies 2004, Lalander 2004, Stallwitz 2012). In combination theory and empirical evidence can be employed to identify the current state of an illegal drug subculture, compare it in its hitherto course with other drug scenes to prognosticate its probable future developments and design location-specific efficient interventions. 
Community-Mindedness: Protection against Crime in the Context of Illicit Drug Cultures? Stallwitz

\section{Endnotes}

${ }^{1}$ Kroeber and Kluckhohn provide a more detailed definition of culture that emphasizes the reciprocal relationships between behavior, ideas, and values. Moreover, they emphasize the relevance of implicit cultural patterns and symbols (1952, p. 181): "Culture consists of patterns, explicit and implicit, of and for behavior acquired and transmitted by symbols, constituting the distinctive achievements of human groups, including their embodiments in artifacts; the essential core of culture consists of traditional (i.e. historically derived and selected) ideas and especially their attached values; culture systems may, on the one hand, be considered as products of action, and on the other as conditioning elements of further action."

${ }^{2}$ In an investigation about aboriginal women survivors of sexual abuse McEvoy and Daniluk define community-mindedness as "the sense of understanding that, individual actions, both positive and negative, reflect on the entire community" (1995), hence exclusively referring to the social caring aspect of the dichotomous conception employed in this study. Alfred Adler, in contrast, speaks about a community sprit (Gemeinschaftsgefühl) as an attitude leading to a "we", which refers to the ability and preparedness to co-operate with other people regarding the common weal (1973). With an increasing sense of community, the degree of social control also intensifies, since due to the strong focus on the common good everything that does not correspond to and thus endangers the corporate feeling is rejected and regarded as deviant. The definition of community-mindedness as used in this study also contains these two sides, community spirit and social control (as cited in Stallwitz 2012, p. 174).

${ }^{3}$ It is now called the Community Alcohol and Drugs Services Shetland (CADSS).

${ }^{4}$ Supported by, e.g., Highlands \& Islands Enterprise (HIE) (2007), Stallwitz (2007), and Shetland Island Council (2011, p. 47); crime rates in Shetland amount to 322 crimes per 10,000 of the population in 2004/2005 compared to the Scottish rate of 863 per 10,000 of the population (HIE, 2007).

${ }^{5}$ Very low levels of socio-economic deprivation are also confirmed by the Scottish Index of Multiple Deprivation (SIMD) (2012).

${ }^{6}$ Virtually no homelessness and one of the lowest unemployment rates across Britain are stated by HIE (2003) and Shetland Islands Council (2008).

${ }^{7}$ Further personal examples additional to the one of Angus are principally provided by all employed heroin users (see table 1 in Appendix 1).

${ }^{8}$ Hadden and Lester (1978) describe how in-group identity is always an ongoing achievement in which group boundaries are collectively generated, affirmed, maintained, and employed to mark differences between insiders and outsiders (as cited in Stallwitz 2012, p. 98).

${ }^{9}$ No obvious trend can be derived from the Scottish Drug Misuse Data, as the percentages vary greatly from year to year, probably due to the comparatively small client numbers. In most years since beginning of reporting for first the Island Boards (Shetland, Orkney and 
Western Isles) in 1999 and since 2004 for Shetland specifically, the percentages of employed clients in Shetland exceeded the national percentages significantly (cf. ISD Scotland 1999 2011). Similar can be observed concerning 'Employment' as source of funding personal drug use (cf. ISD Scotland 2007 - 2010).

${ }^{10}$ The rate of crime was 344 crimes per 10,000 persons in Shetland for the years 2007/2008, versus 749 crimes per 10,000 persons for Scotland during this same period.

${ }^{11}$ A number of interviewed Shetland heroin users describe what could be termed a "Soothmoother influence" on the island heroin scene (e.g. Duncan, N, 9, 12-30; Ben, N, 15, 36 - 16, 15; Mona, C, 4, 29-34; Robin, C, 8, 10 - 39). Hereby urban manners are referred to that are imported both by incoming heroin users from urban Britain as well as Shetlanders who had been in contact with urban heroin scenes.

${ }^{12}$ Between one and two deaths per year as reported by ISD Scotland, $2000-2011$.

${ }^{13}$ Zeitgeist can be understood as a “...psychologically driven socio-cultural phenomenon.

Zeitgeist ...refers to the idea that each period in a society's history can be characterized by a distinct set of cultural beliefs and practices that establish a certain tone that will be reflected in art, politics, and virtually every other aspect of social life" (Crossman 2014, p. 8).

${ }^{14}$ Intensified police enforcement causes an increase in incarcerated Shetland dealers, who are granted the opportunity to connect with other (bigger) dealers and suppliers in prison and who then resume business in a more professionalized manner after release.

${ }^{15}$ ISD Scotland started recording the source of funding drug use of new clients in 2007. The Shetland figures are with $22 \%$ compared to $27 \%$ in Scotland overall, both are which are extremely high. However, the effect of the comparatively small numbers needs to be considered regarding the high number of 22\% in 2007 and also the 0\% in 2010 and 2011. Nonetheless, 14 versus $27 \%$ in 2008 and 11 versus $25 \%$ in 2009 convey the impression that acquisitive crime is existent in Shetland. According to the qualitative findings of the present study acquisitive crime primarily seems to be dealing. No specifying statistical information is available that could support the qualitative data.

${ }^{16}$ See social identity theory according to Tajfel and Turner (1986). 
Community-Mindedness: Protection against Crime in the Context of Illicit Drug Cultures? Stallwitz

\section{References}

Abraham, M. D. (1999). Illicit drug use, urbanization, and lifestyle in the Netherlands. Journal of Drug Issues, 29, 565-586.

Adler, A. (1973). Der Sinn des lebens. Frankfurt a. M.: Suhrkamp. (Original: 1933).

Agar, M. (1999). How to ask for a study in qualitatisch. Qualitative Health Research, 9, 684697.

Aitken, C., Moore, D., Higgs, P., Kelsall, J., \& Kerger, M. (2002). The impact of a police crackdown on a street drug scene: evidence from the street. International Journal of Drug Policy, 13, 193-202.

Aldaz, E., Wagner, F., Diaz, D. B., Lopez, A., \& Collado, M. E. (2002). Social cohesion, cultural identity, and drug use in Mexican rural communities. Substance Use \& Misuse, 37, 715-747.

Anderson, S., \& Frischer, M. (1997). Drug misuse in Scotland: Findings from the 1993 and 1996 Scottish Crime Surveys. Crime and Criminal Justice Findings No. 17. Edinburgh: Scottish Executive Central Research Unit.

Ansari, S. (2013). Social Capital and Collective Efficacy: Resource and Operating Tools of Community Social Control. Journal of Theoretical and Philosophical Criminology Social Capital \& Collective Efficacy, 5, 75-94.

Baier, C. (2004). Substitutionsbehandlung Opiatabhängiger im ländlichen Bereich. Eine qualitative Interview-Studie mit Patienten und Ärzten. Berlin: Verlag für Wissenschaft und Bildung.

Bandura, A. (1977). Social learning theory. Englewood Cliffs, NJ: Prentice Hall.

Becker, H. S. (1963). Outsiders: Studies in the sociology of deviance. New York: Free Press.

Biernacki, P., \& Waldorf, D. (1981). Snowball sampling: problems and techniques of chain referral sampling. Sociological Methods and Research, 10, 141-163.

Blumer, H. (1969) Symbolic Interactionism: Perspective and method. Englewood Cliffs, NJ: Prentice-Hall.

Bundeszentrale für politische Bildung. (2009). Bundeszentrale für politische Bildung (2009). Subkultur. Retrieved 07/07/09 from http://www1.bpb.de/popup/popup_lemmata.html?guid=M7LG1W.

CADSS. (2012). Annual Report Community Alcohol \& Drugs Services Shetland 2011/2012. Lerwick: CADSS. 
Chengzheng, Z., Zhimin, L., Dong, Z., Yanhong, L., Jianhui, L., Yilang, T., Zeyuan, L., \& Jiwang, Z. (2004). Drug abuse in China. Annals of the New York Academy of Sciences, $1025,439-445$.

Coomber, R. (2004). Editorial: Drug use and drug market intersections. Addiction Research and Theory, 12, 501-505.

Crossman, A. (2014). Zeitgeist. Retrieved 14/02/2014 from http://sociology.about.com/od/Z_Index/g/Zeitgeist.htm.

Curtis, R. (2003). Crack, cocaine and heroin: Drug Eras in Williamsburg, Brooklyn, 19602000. Addiction Research and Theory, 11, 47-63.

Day, C., Conroy, E., Lowe, J., Page, J., \& Dolan, K. (2006). Patterns of drug use and associated harms among rural injecting drug users: Comparisons with metropolitan injecting drug users. Australian Journal of Rural Health. 14, 120-125.

Dean, A. (1990). Culture and community: drink and soft drugs in the Hebridean youth culture. Sociological Review. 38, 517-563.

Dean, A. (1995) Space and substance misuse in rural communities. The International Journal of Sociology and Social Policy, 15, 134-155.

Dean, A. (2001). Complexity and substance misuse. Addiction Research \& Theory, 9, 19-41.

Deller, S. C., \& Deller, M. A. (2010). Rural crime and social capital. Growth and Change, 41, 221-275.

Directferries (2013). Ferry routes. Retrieved 10/11/2013 from http://www.directferries.co.uk/routes.htm.

Donnermeyer, J. F. (1992). The use of alcohol, marijuana, and hard drugs by rural adolescents: A review of recent research. In: Edwards, R., ed. Drug Use in Rural American Communities (pp. 31-75). Binghamton, NY: Harrington Park Press, Inc.

Donnermeyer, J. F., Scheer, S. D., \& Borden, L. M. (2000). The relationship between family factors and adolescent substance use in rural, suburban, and urban settings. Journal of Child and Family Studies, 9, 105-115.

Donnermeyer, J. F. (2007). Rural crime: Roots and restoration. International Journal ofRural Crime, 1, 2-20.

Donnermeyer, J. F. \& DeKeseredy, W. S. (2008). Toward a rural critical criminology. Southern Rural Sociology, 28, 4-28.

Effective Interventions Unit. (2005). Service provisions for drug users in rural and remote areas of Scotland: A qualitative study. Edinburgh: Scottish Executive's Substance Misuse Research Team (SMRT). 
Community-Mindedness: Protection against Crime in the Context of Illicit Drug Cultures? Stallwitz

Forsyth, A. J. M., \& Barnard, M. (1999). Contrasting levels of adolescent drug use between adjacent urban and rural communities. Glasgow: Centre for Drug Misuse Research, University of Glasgow.

Gardner, B. W., \& Peck, D. F. (1996). Drug use in the Scottish Highlands. Drugs: Education, Prevention and Policy, 3, 285-294.

Glaser, B. G., \& Strauss, A. L. (1967). The discovery of grounded theory: Strategies for qualitative research. Chicago: Aldine Publishing Company.

Golub, A., Johnson, B. D., \& Dunlap, E. (2005). Subcultural evolution and illicit drug use. Addiction Research \& Theory, 13, 217-229.

Grund, J.-P. C. (1993). Drug use as a social ritual: Functionality, symbolism and determinants of self-regulation. Rotterdam: IVO Reeks.

Hadden S.D., \& Lester, M. (1978). Cited in: M.J. McCallion (2007). Social Psychology. Sociology of groups. In-groups and out-groups. In: Blackwell Encyclopedia of Sociology Online. Retrieved 12/10/2013 from http://www.sociologyencyclopedia.com/public/.

Hammersley, R., Jenkins, R., \& Reid, M. (2001). Cannabis use and social identity. Addiction Research \& Theory, 9, 133-150.

Hardenbergh, D., Stillner, V., Kraus, R. F., Leukefeld, C. G. (1999). Drug use in very rural Alaska villages. Substance Use \& Misuse, 34, 579-593.

Harding, W. M. \& Zinberg, N. E. (1977). The effectiveness of the subculture in developing rituals and social sanctions for controlled drug use. In B. M. DuToit, (ed.), Drugs, rituals and altered states of consciousness (pp. 111-133). A.A. Rotterdam: Balkema.

Hay, G. \& Gannon, M. (2006). Capture-recapture estimates of the local and national prevalence of problem drug use in Scotland. International Journal of Drug Policy, 17, 203-210.

Hay, G., McKeganey, N., \& Hutchinson, S. (2001). Estimating the national and local prevalence of problem drug misuse in Scotland. Executive report. Glasgow: Scottish Centre for Environmental Health.

Hay, G., Gannon, M., McKeganey, N., Hutchinson, S., \& Goldberg, D. (2005). Estimating the national and local prevalence of problem drug misuse in Scotland. Executive report. Glasgow: Centre for Drug Misuse Research, University of Glasgow.

Hay, G., Gannon, M., Casey, J., \& McKeganey, N. (2009). Estimating the National and Local Prevalence of Problem Drug Misuse in Scotland. Executive Report. Glasgow: Centre for Drug Misuse Research, University of Glasgow. 
Highlands and Islands Enterprise. (2003). Shetland Islands economic update. Retrieved February 14, 2007, from http://www.shetland.gov.uk/datashare/upload/documents/HIEshetland-areaeconomic-pro fi le-2003.pdf.

Highlands and Islands Enterprise. (2007). Economic update: Shetland. April 2007. Retrieved 15/02/2007 from http://www.hie.co.uk/about-hie/policies-and-publications/default.html.

Highlands and Islands Enterprise. (2007). Economic update: Shetland. April 2007. Retrieved February 15, 2007, from http://www.hie.co.uk/about-hie/policies-andpublications/default.html .

Hillmann, J. (1994). Die suche nach innen : Psychologie und Religion. Einsiedeln: Daimon Verlag.

Hofstede, G. (1980). Culture's consequences: International differences in work-related values. London: Sage Publications.

ISD Scotland. (2004-2011). Drug misuse statistics Scotland. Edinburgh: ISD.

Johnston, L. D., O’Malley, P. M., \& Bachman, J. G. (1993). National survey results on drug use from the Monitoring the Future Study, 1975-1992. Washington, DC: US Government Printing Office.

Kemmesies, U. E. (2004). Zwischen rausch und realität: Drogenkonsum im bürgerlichen Milieu. Wiesbaden: VS Verlag für Sozialwissenschaften.

Kroeber, A. L., \& Kluckhohn, C. (1952). Culture: A critical review of concepts and definitions. Harvard University Peabody Museum of American Archeology and Ethnology Papers, 47, 181.

Lalander, P. (2003). Hooked on heroin: Drugs and drifters in a globalized world. Oxford/ New York: Berg/Oxford International Publishers.

Lempens, A., van de Mheen, D., \& Barendregt, C. (2003). Homeless drug users in Rotterdam, The Netherlands: Profile, way of life, and the need for assistance. Substance Use and Misuse, 38, 339-375.

Li, Y. Y. (2011). Social Structure and Informal Social Control in Rural Communities. International Journal of Rural Criminology, 1, 63-88.

Lucchini, R. (1985). Young drug addicts and the drug scene. Bulletin on Narcotics, 3, 135148.

Maslow, A. (1948). 'Higher' and 'Lower' Needs. Journal of Psychology, 25, 433-436.

Maslow, A. (1954). The Instinctoid Nature of Basic Needs. Journal of Personality, 22, 326347. 
Community-Mindedness: Protection against Crime in the Context of Illicit Drug Cultures? Stallwitz

May, T., \& Hough, M. (2004). Drug markets and distribution systems. Addiction Research \& Theory, 12, 549-563.

McCurdy, S. A., Williams, M. L., Kilonzo, G. P, Rossi, M. W., \& Leshabari, M. T. (2005). Heroin and HIV risk in Dar es Salaam, Tanzania: Youth hangouts, mageto and injecting practices. AIDS Care, 17, Supplement 1, S65-S76.

McEvoy, M. \& Daniluk, J. (1995). Wounds to the soul: The experiences of aboriginal women survivors of sexual abuse. Canadian Psychology, 36, 221-235.

McNicoll, A. (2010). High tide: Shetland's remote but affluent island communities are facing up to the reality that, unlike the rest of Britain, rising numbers of young people are taking up heroin. Andy McNicoll investigates. DrugLink, 25, 10-11.

McSweeney, T., \& Turnbull, P. J. (2007). Exploring user perceptions of occasional and controlled heroin use: A follow-up study. York: Joseph Rowntree Foundation.

McSweeney, T., Turnbull, P. J., \& Hough, M. (2008). The treatment and supervision of drug dependent offenders: A review of the literature prepared for the UK Drug Policy Commission. London: UK Drug Policy Commission.

McVie, S. \& Norris, P. (2006). Neighbourhood effects on youth delinquency and drug use. The Edinburgh Study of Youth Transitions and Crime. Edinburgh: Centre for Law and Society. University of Edinburgh.

Mead, G.H. (1956). The social psychology of George Herbert Mead. Edited with an introduction by Anselm Strauss. Chicago, Ill.: University of Chicago Press.

Mojtahedzadeh, V., Razani, N., Malekinejad, M., Vazirian, M., Shoaee, S., Saberi Zafarghandi, M., Hernandez, A., \& Mandel, J. (2008). Injection Drug Use in Rural Iran: Integrating HIV Prevention into Iran's Rural Primary Health Care System. AIDS \& Behavior, 12 Sup 1, 7-12.

Morenoff, J. D., Sampson, J. S. \& Raudenbush, S. W. (2001). Neighbourhood inequality, collective efficacy, and the spatial dynamics of urban violence. Criminology, 39, 517558.

National Records of Scotland, (2013). Mid-2011 and Mid-2012 Population estimates Scotland. population estimates by sex, age and administrative area. Edinburgh: General Register Office for Scotland.

Nguyen, V. T. \& Scannapieco, M. (2008). Drug abuse in Vietnam: a critical review of the literature and implications for future research. Addiction, 103, 535-543.

Office of National Drug Control Policy (ONDCP). (1997). Pulse check national trends in drug abuse. Washington, DC: Office of National Drug Control Policy. 
Parker, H. (2005). Normalization as a barometer: Recreational drug use and the consumption of leisure by younger Britons. Addiction Research \& Theory, 13, 205-215.

Parker, H., Aldridge, J., \& Measham, F. (1998). Illegal leisure. London: Routledge.

Putnam, R. D. (1993). The prosperous community: Social capital and public life. The American Prospect, Spring, 13, 35-42.

Putnam, R. D. (2000). Bowling Alone. The collapse and revival of American Community. London: Simon and Schuster.

Radcliffe-Brown, A. R. (1952). Structure and function in primitive society: Essays and addresses. Glencoe, IL: Free Press.

Sampson, R. J. (2012). Great American city: Chicago and the enduring neighborhood effect. Chicago: The University of Chicago Press.

Sampson, R. J. (2004). Neighborhood and Community: Collective Efficacy and Community Safety. New Economy, 11, 106-113.

Sampson, R. J., Raudenbush, S. W., \& Earls, F. J. (1997). Neighbourhoods and violent crime: A multilevel study of collective efficacy. Science, 277, 918-924.

San Jose. (2006). Übersicht: Lage der Shetlandinseln (rot). Wikimedia Commons. Retrieved 26/02/2014 from http://commons.wikimedia.org/wiki/File:Shet-nors.png.

Schulenberg, J., Maggs, J. \& Hurrelmann, K. (Eds.). (1997). Health risks and developmental transitions during Adolescence. New York: Cambridge University Press.

Scottish Executive. (2006). Urban-rural classification 2005-2006. Edinburgh: Scottish Executive.

Scottish Government. (2012). Scottish index of multiple deprivation (SIMD). General report. Edinburgh: Scottish Government. Retrieved 12/10/2013 from http://simd.scotland.gov.uk/publication-2012/.

Shetland Islands Council. (2008). Economic development policy statement 2007 - 2011. Lerwick.

Shetland Islands Council. (2009). Ports and harbours in Shetland. Retrieved September 20, 2009, from http://www.shetland.gov.uk/ports/.

Shetland Islands Council. (2010). Community profile central mainland. Lerwick: Shetland Islands Council, Economic Development Unit.

Shetland Island Council. (2011). Shetland in statistics. Lerwick: Economic Development Unit, Shetland Islands Council, $38^{\text {th }}$ edition. 
Community-Mindedness: Protection against Crime in the Context of Illicit Drug Cultures? Stallwitz

Spunt, B. (2003). The current New York City heroin scene. Substance Use and Misuse, 38, 1539-1549.

Stallwitz, A. \& Shewan, D. (2004). A qualitative exploration of the impact of cultural and social factors on heroin use in Shetland (Scotland). Journal of Psychoactive Drugs, 36, 367-378

Stallwitz, A. (2007). Heroin use in Shetland from the perspective of different local professionals. Therapeutic Communities, 28, 256-272.

Stallwitz, A. (2012). The role of community-mindedness in the self-regulation of drug cultures. A case study from the Shetland Islands. Dordrecht, London, New York: Springer.

Strauss, A.. \& Corbin, J. (1998). Basics of qualitative research. London: Sage Publications.

Tajfel, H.. \& Turner, J. C. (1986). The social identity theory of intergroup behavior. In S. Worchel \& W. G. Austin (eds.), Psychology of intergroup relations (pp.7-24). Chicago: Nelson- Hall.

Taylor, S. J., \& Bogdan, R. (1998). Introduction to qualitative research methodology: A Guidebook and resource . Toronto: Wiley.

The Guardian (23/04/2008). Heroin death exposes Shetland drugs blight. Retrieved 09/02/09 from http://www.guardian.co.uk/uk/2008/apr/23/scotland.drugstrade.

The Times Online. (18/08/2007). Heroin teenager's death exposes drug menace gripping Shetland. Retrieved [22/09/08] from http://www.timesonline.co.uk/tol/news/uk/article2280651.ece.

Thrasher, F. (1927). The Gang. Chicago: University of Chicago Press.

Visit Shetland. (2013). Lerwick - Shetland's capital. Retrieved 21/10/2013 from http://visit.shetland.org/lerwick.

Waitzfelder, B., Engel, C. \& Gilbert, F. (1998). Substance Abuse in Hawaii: Perspectives of Key Local Human Service Organizations. Substance Abuse, 19, 7-22.

Warburton, H., Turnbull, P. J., \& Hough, M. (2005). Occasional and controlled heroin use: Not a problem? London: King's College.

Wills, J. (1991). A Place in the sun: Shetland and oil. Edinburgh: Mainstream Publishing Company.

Young, J. (1971). The drug takers. The social meaning of drug use. London: Cox \& Wyman Ltd. 
International Journal of Rural Criminology, Volume 2, Issue 2 (June), 2014

Zinberg, N. E. (1984). Drug, set, and setting. The basis for controlled intoxicant use. New Haven: Yale University Press. 
Community-Mindedness: Protection against Crime in the Context of Illicit Drug Cultures? Stallwitz

Appendix 1: Participant characteristics (cf. Stallwitz, 2012, p. 79)

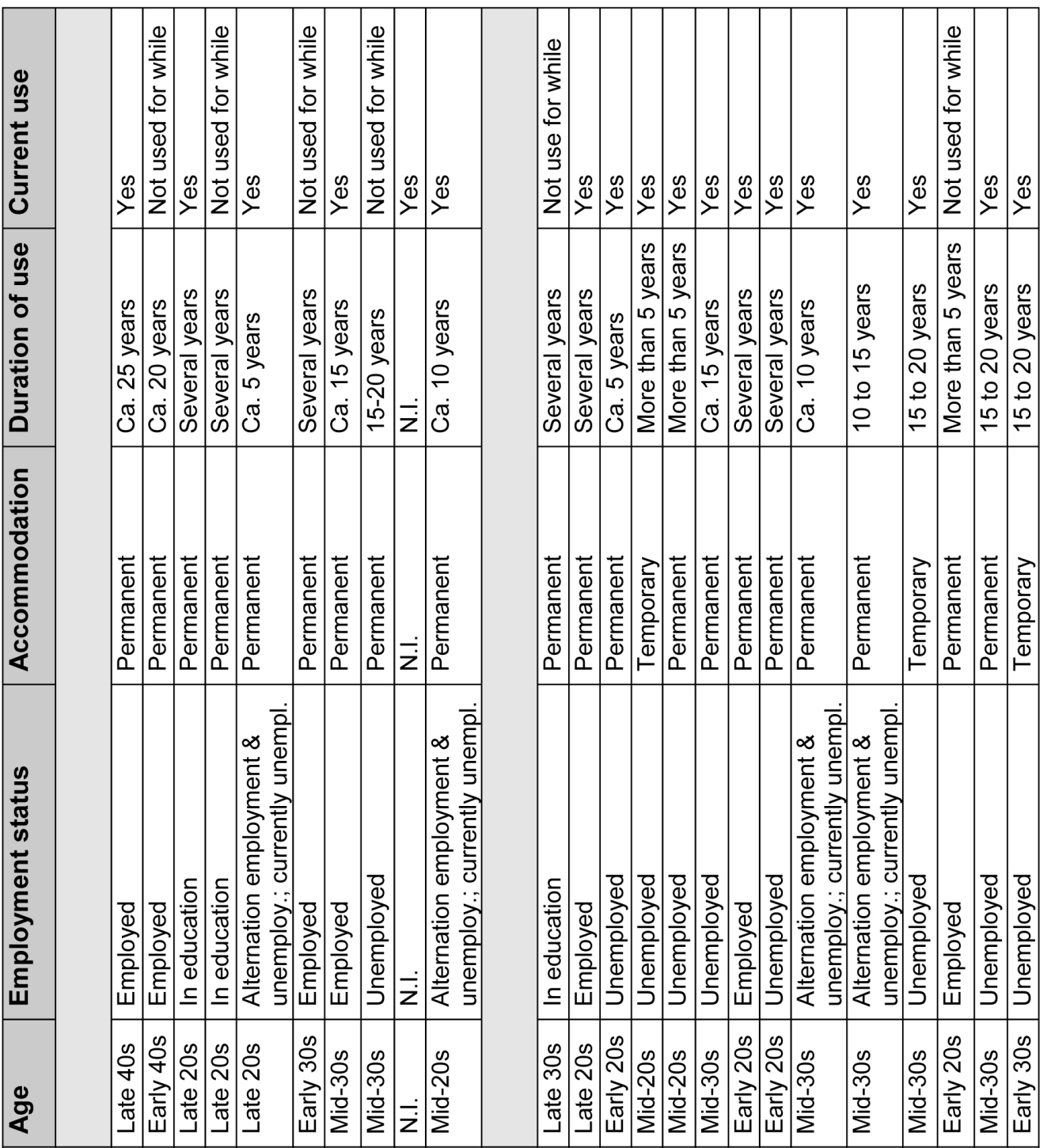

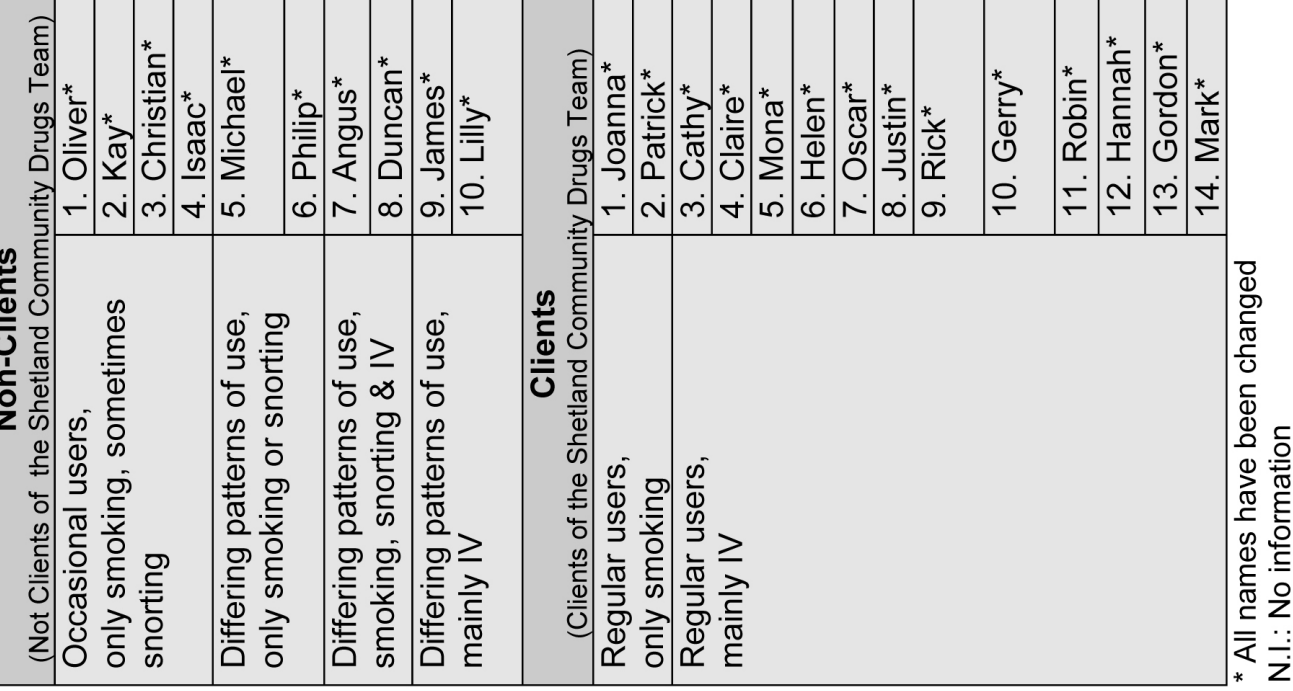




\section{Appendix 2: Interview guidelines (cf. Stallwitz, 2012, 367-369)}

\section{INTERVIEW GUIDELINES}

\section{Personal details}

1.1. Age

1.2. Where born? Since when in Shetland? Ever lived anywhere else - where, how long for? When and why returned to Shetland?

1.3. Employment status, source of income, job, education

1.4. Marital status, living conditions, children etc.

\section{Personal heroin using history}

3.1. [Initiation of heroin use] When started using heroin? How and why started? Who with? What kind of situation?

3.2. [Course \& development of heroin use patterns until now] How did your heroin use develop? Patterns of use changed over time? Which way? Caused by what? Any relevant life experiences, which had an impact on your use?

3.3. Changes in using patterns, how, why, how related to general changes in heroin scene?

\section{Current patterns of use}

4.1 Frequency and amount? Depending on what how often and how much? Route of administration? Always the same, changing - why?

4.2. Use of any other drugs? In what kind of relation to heroin use? Poly drug use?

4.3. Heroin use any influence on life style - work, leisure activities, circle of friends etc.?

4.4 [Setting of heroin use] Could you describe the situations in which you are using? Where, who with (alone, friend(s), group of people, scene etc.) what kind of occasion?

4. Personal meaning of heroin/heroin use (Personal relationship to heroin use and 'heroin high')

4.1. [Set of heroin use] What are your expectations from your use? Your motivations why you use?

4.2. Function of heroin use

4.3. [Cost and benefit] Good and down sides of heroin use Attitudes towards personal use? E.g. clear and relaxed? Positive or negative? Ambivalent? Need to justify in order to avoid cognitive and emotional dissonances, inner conflicts between desire for 'high' and society's moral attitude etc.?

4.5. Heroin use and awareness of own life/life style? Heroin use and philosophy or ideology? 
Community-Mindedness: Protection against Crime in the Context of Illicit Drug Cultures? Stallwitz

\section{Heroin scene in Shetland}

5.1. Is there a (main) heroin scene/subculture in Shetland? What is it like? Characteristics?

5.2. Are there different heroin using subgroups or -scenes? Can you describe them in more detail (for example, different age groups, different patterns of use, different meaning of the drug etc.)?

5.4. What are the Shetland-specific characteristics in comparison to other urban and rural scenes on the Scottish/English mainland?

5.5. What is the heroin scene like today compared to the past? Has it changed?

\section{Heroin use and identity (Self-esteem and-confidence)}

6.1. Own social role within the broader and immediate Shetland community?

6.2. Would you describe yourself as belonging to a certain drug using subculture/scene (these days)? If yes, could you describe this scene in more detail?

6.3. Would you call yourself a heroin user, dope smoker, "boozer" etc. (these days)?

6.4. Relationship societal and subcultural identity, identification with subculture or rather general society?

6.5. Have you ever been involuntarily found out to be a heroin user (someone previously not informed - who?) If yes, what were the consequences? Reactions - e.g. sanctions - of friends, family, general community?

\section{Control over personal heroin use}

7.1. What do think about heroin and addiction?

7.2. In how far do you feel in charge of your substance use in general and your heroin use in particular? Could you imagine to ever become "addicted"? How?

7.3. Could you tell me a bit about your own norms, values, personal limits, taboos regarding your heroin use/heroin use within your social circle? What is acceptable, what isn't? Any sanctions if limits not kept?

7.4. Are there certain rituals involved in your use?

7.5. How do you keep control? Automatically? Consciously? If yes, can you describe your "control mechanisms" in detail? How did you acquire them - learned yourself? From friend(s)/heroin using scene? Have they always been the same or changed over time, e.g. according to changing life situation or life events?

7.6. How do you deal with cravings, other triggers?

7.7. Do you think, to keep control over one's heroin use is easier in Shetland than anywhere else? If yes, can you outline that, please? 


\section{Appendix 3: Structural model (cf. Stallwitz, 2012, p. 195)}

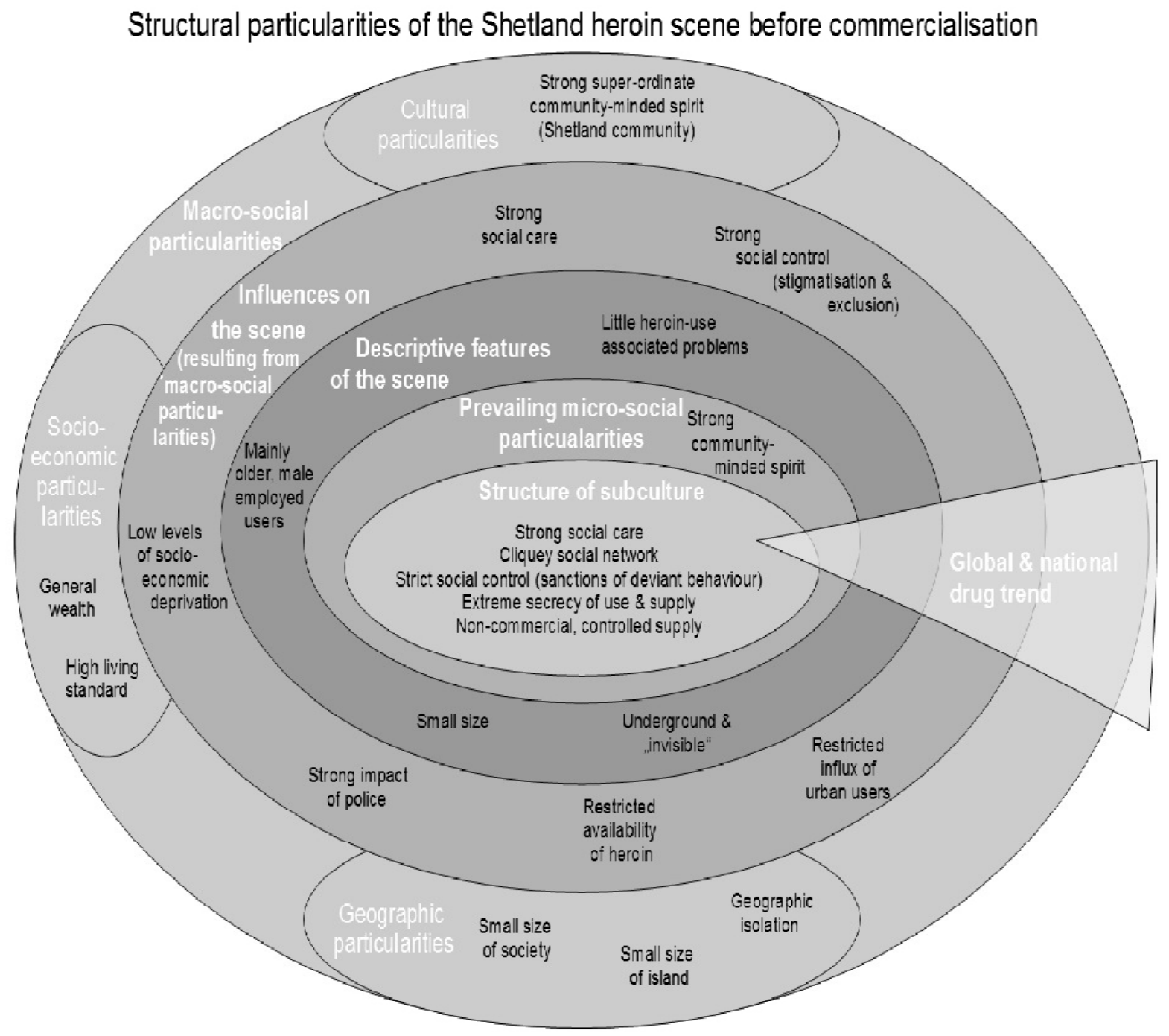

